\title{
Antenatal Dexamethasone Treatment Induces Sex- dependent Up-regulation of NTPDase1/CD39 and Ecto-5囚-nucleotidase/CD73 in the Rat Fetal Brain
}

\section{Milica Manojlovic-Stojanoski}

University of Belgrade Institute for Biological Research Sinisa Stankovic: Univerzitet u Beogradu Institut za bioloska istrazivanja Sinisa Stankovic

Irena Lavrnja

IBISS: Univerzitet u Beogradu Institut za bioloska istrazivanja Sinisa Stankovic

Ivana Stevanovic

VMA: Vojnomedicinska akademija

\section{Svetlana Trifunovic}

Univerzitet u Beogradu Institut za bioloska istrazivanja Sinisa Stankovic

\section{Natasa Ristic}

Univerzitet u Beogradu Institut za bioloska istrazivanja Sinisa Stankovic

\section{Natasa Nestorovic}

University of Belgrade Institute for Biological Research Sinisa Stankovic: Univerzitet u Beogradu Institut za bioloska istrazivanja Sinisa Stankovic

\section{Jean Sévigny}

Université Laval Faculté de médecine: Universite Laval Faculte de medecine

\section{Nadezda Nedeljkovic}

Univerzitet u Beogradu Bioloski Fakultet

Danijela Laketa ( $\sim$ danijela@bio.bg.ac.rs)

University of Belgrade Faculty of Biology https://orcid.org/0000-0002-6563-8924

\section{Research Article}

Keywords: antioxidant system, ectonucleotidases, glucocorticoids, neurodevelopment, oxidative stress, purinergic signaling

Posted Date: February 24th, 2021

DOI: https://doi.org/10.21203/rs.3.rs-231022/v1

License: (c) (1) This work is licensed under a Creative Commons Attribution 4.0 International License.

Read Full License 
Version of Record: A version of this preprint was published at Cellular and Molecular Neurobiology on March 24th, 2021. See the published version at https://doi.org/10.1007/s10571-021-01081-8. 


\section{Abstract}

Dexamethasone (DEX) is frequently used to treat women at risk of preterm delivery, but although indispensable for completion of organ maturation in fetus, antenatal DEX treatment may exert adverse sex-dimorphic neurodevelopmental effects. Literature findings implicated oxidative stress in adverse effects of DEX treatment.. Purinergic signalling is involved in neurodevelopment, and controled by ectonucleotidases, among which in the brain are most abundant ectonucleoside triphosphate diphosphohydrolase 1 (NTPDase1/CD39) and ecto-5囚-nucleotidase (e5『NT/CD73), which jointly dephosphorylate ATP to adenosine. They are also involved in cell adhesion and migration, critical for brain development. Up-regulation of CD39 and CD73 after DEX treatment was reported in adult rat hippocampus. We investigated the effects of maternal DEX treatment on CD39 and CD73 expression and enzymatic activity in the rat fetal brain of both sexes, in the context of oxidative status of the brain tissue. Fetuses were obtained at embryonic day (ED) 21, from Wistar rat dams treated with $0.5 \mathrm{mg} \mathrm{DEX} / \mathrm{kg} / \mathrm{day}$, at ED 16,17, and 18, and brains were processed and used for further analysis. Sex-specific increase in CD39 and CD73 expression and in the corresponding enzyme activities was induced in the brain of antenatally DEX-treated fetuses, more prominently in males. The oxidative stress induction after antenatal DEX treatment, was confirmed in both sexes, altghough showing a slight bias in males. Due to involvement of purinergic system in crucial neurodevelopmental processes, future investigations are needed to determine the role of observed changes in the adverse effects of antenatal DEX treatment.

\section{Introduction}

Glucocorticoids (GCs - cortisol in humans, corticosterone in rodents) play a crucial role in a proper and timely completion of organogenesis during fetal development particularly, in the maturation of lungs and the brain (Moisiadis and Matthews 2014a; Moisiadis and Matthews 2014b). In preterm infants due to insufficient exposure to endogenous GCs, complications such as respiratory distress syndrome, intraventricular hemorrhage or necrotizing enterocolitis are common (Carson et al. 2016), covering approximately $18 \%$ of 5,9 million annual deaths before the age of 5 in 2015 worldwide (Liu et al. 2016). Therefore, in developed countries expecting mothers with the risk of preterm delivery usually receive hormonal therapy with synthetic GCs, either dexamethasone (DEX) or betamethasone (BMS), between $24^{\text {th }}$ and $34^{\text {th }}$ gestational week (Antenatal corticosteroids revisited: repeat courses - National Institutes of Health Consensus Development Conference Statement, August 17-18, 2000 2001). It is important to note that not just insufficient, but also excessive prenatal exposure to GCs may have detrimental effects on brain development and functions (Davis et al. 2013; Fukumoto et al. 2009; Matthews 2000). Maternal treatment with DEX or BMS promotes an excessive GC stimulation in fetuses, since synthetic GCs exert 25 times higher genomic potency than natural occurring GCs (Jobe and Soll 2004). Also, in comparison to cortisol, synthetic GCs more readily enter the fetal circulation and directly diffuse through the bloodbrain barrier into the brain (Damsted et al. 2011), due to considerably lower inactivation by placental enzyme $11 \beta$-hydroxysteroid dehydrogenase 2 (Chapman et al. 2013). It was shown that antenatal DEX treatment and excessive GC exposure have long-term neurodevelopmental consequences, which may be 
sex-specific both in human (Davis and Pfaff 2014; Wallensteen et al. 2016) and in animal offspring (Caetano et al. 2017; Matthews 2000). Thus, although prenatal GC treatment largely reduces risks of premature delivery, it increases the risk of neurodevelopmental complications and consequent adverse behavioral effects, such as hyperactivity (French et al. 2004), and affective problems (Davis et al. 2013) in children.

Purinergic signaling encompasses signaling molecules - ATP, ADP and adenosine, nucleotide-sensitive P2 and adenosinergic P1 receptors, as well as ectonucleotidase enzymes (Burnstock 2014). Most abundant ectonucleotidases in the CNS are ectonucleoside triphosphate diphosphohydrolase 1 (NTPDase1/CD39) and ecto-5'-nucleotidase (e5囚NT/CD73) (Braun et al. 2000; Zimmermann 1992) which in co-action completely dephosphorylate ATP to adenosine (Yegutkin 2008). NTPDase1/CD39 (EC 3.6.1.5) is a membrane ectoenzyme with seven potential $\mathrm{N}$-glycosylation sites, and apparent molecular weight 70-100 kDa (Kaczmarek et al. 1996; Zimmermann et al. 2012). It hydrolyses ATP and ADP with a ratio of $\sim 1: 1-1,5$ (Kukulski et al. 2005), leading to the rapid generation of AMP as a final product. The latter is then hydrolyzed to adenosine by e5『NT/CD73 (EC 3.1.3.5), a GPI-anchored membrane ectoenzyme, with five potential $\mathrm{N}$-glycosylation sites in rodents and an apparent molecular weight from 60-80 kDa (Vogel et al. 1991; Zimmermann 1992; Zimmermann et al. 2012). Purinergic signaling plays a major role during fetal development (Burnstock and Dale 2015; Del Puerto et al. 2013), being involved in processes such as generation and migration of neurons and glia, and development of synapses, which are critical to the brain cytoarchitecture and connectivity (Rodrigues et al. 2019). Nevertheless, literature data are mostly referred to purinergic receptors, while data on the role of enzymes that regulate extracellular purine levels are still scarce. Several studies reported the involvement of CD73 in postnatal rodent brain development showing its association with migrating immature neurons and developing synapses in cerebellum of neonatal rats (Fenoglio et al. 1995) and mice (Bailly et al. 1995), and demonstrating its developmental increase in expression and enzymatic activity in rat hippocampus (Grkovic et al. 2014). In addition to enzymatic role in purinergic signaling, involvement in cellular adhesion and migration was shown by multiple studies for CD39 in human lymphocytes, and for CD73 in rat astrocytes (Adzic and Nedeljkovic 2018), chicken embryonic fibroblasts (Codogno et al. 1988), human lymphocytes (Airas et al. 1995), and various cancer cells (Flocke et al. 1992; Sadej et al. 2008). Therefore, it is reasonable to assume that changes in expression of both ectonucleotidases may affect proliferation, differentiation and other developmental processes in the nervous system. It was shown that DEX treatment induced up-regulation of CD73 and CD39, as well as increase of ectonucleotidase activities in the hippocampus of adult male rats (Drakulić et al. 2015). Also, adenosine signaling was involved in gender-specific microglial remodeling induced by antenatal DEX treatment in the prefrontal cortex of rat offspring, which also displayed anxious phenotype (Caetano et al. 2017). DEX treatment induced lasting changes in cellular functions and increased susceptibility to oxidative stress in embryonic neural stem cells, and in cerebellar granule cells from antenatally treated rats (Ahlbom et al. 2000; Bose et al. 2010). Pro-oxidative effects of excessive GCs exposure were also documented in vivo in the rat brain (Mclntosh et al. 1998; Sato et al. 2010) Imbalance between pro- and antioxidants, termed "oxidative stress" (Sies 1985), may occur either due to accumulation of reactive oxygen and nitrogen 
species (ROS and RNS, respectively), or depletion of antioxidants (Sies 1997, Birben 2012). In the brain, oxidative stress is involved in various pathologies such as ischemic damage (Chan 1996), excitotoxicity (Mattson et al. 1995), and neurodegeneration (Andersen 2004), due to particularly high susceptibility of the mammalian brain to oxidative damage (Halliwell 2001). The primary antioxidant defense system comprises enzymatic antioxidants - superoxide dismutase (SOD), glutathione peroxidase (GPx), catalase (CAT), and nonenzymatic antioxidants among which thiol-containing tripeptide glutathione (GSH) is major soluble antioxidant (Birben et al. 2012; Sies 1997). SOD (EC 1.15.1.1) catalyzes dismutation of superoxide anion radical $\left(\mathrm{O}_{2}{ }^{\circ}\right)$ to molecular oxygen and hydrogen peroxide, which is further removed by GPx (EC 1.11.1.9) through reduction to water, coupled with oxidation of GSH to oxidized gluthatione (GSSG) (Halliwell 2006). Additionally, $\mathrm{H}_{2} \mathrm{O}_{2}$ is decomposed to water and oxygen by CAT (EC 1.11.1.6) . It was convincingly demonstrated that DEX treatment through glucocorticoid receptor (GR) signaling decreases transcriptional activation of antioxidant genes by Nrf2 (Alam et al. 2017), which is a key transcription activator mediating their inducible expression (Kobayashi et al. 2004). Such finding indicates that decreased cellular antioxidant capacity may at least partly account for side effects of antenatal DEX treatment.

Together, literature findings indicate involvement of ectonucleotidases in sex-dimorphic neurodevelopmental changes in response to maternal DEX treatment. Given the fact that DEX is administered in pregnant women whenever a delivery before 34 weeks is anticipated, we have set the goal to assess the effects of prenatal DEX administration on purinergic system activity in male and female rat fetal brain. We hypothesized that antenatal DEX treatment induces changes in expression of CD39 and CD73 in the rat fetal brain, in sex-dependent manner,. thus interfering with neurodevelopmental processes and possibly contributing to adverse effects of treatment. Since literature data strongly imply association of DEX treatment with oxidative stress, which is also involved in different brain pathologies, our additional goal was to assess the effects of antenatal DEX treatment at oxidative/nitrosative stress parameters in the rat fetal brain and their possible involvement in detrimental effects of such treatment in the offspring.

\section{Materials And Methods}

\section{Experimental animals}

Wistar (RRID:RGD_13508588) female and male rats were reared at the Institute for Biological Research in Belgrade, under standard conditions of controlled temperature $\left(22^{\circ} \mathrm{C}\right)$ and a $12 \mathrm{~h}$ light/dark cycle, and freely available food and water. Three-month-old females with regular four-day estrous cycle were selected to mate. Then, females during estrous phase and male rats, arbitrarily chosen from the local colony, weighing approximately 250 and $400 \mathrm{~g}$, respectively, were mated during the night. The embryonic day 0 (EDO) was declared the day when sperm-positive smears were obtained in the morning. Study design is presented at Fig 1. Pregnant females (10 animals) were housed individually in plastic cages. The dams ( 5 animals) received subcutaneously $0.5 \mathrm{mg}$ dexamethasone (DEX)/ $\mathrm{kg} / \mathrm{day}$, for three 
consecutive days at 10A.M., on ED 16,17, and 18, while the control dams (5 animals) received the same volume of saline. The dosing regimen used in the present study has been previously adopted and designated to fall within the range of clinical application in women in obstetric practice (Carbone et al. 2012a). The control fetuses, $n=23$ females $(C f), n=23$ males $(C m)$, and maternally DEX-treated $n=23$ females (Df) and n=23 males (Dm) were obtained on embryonic day 21 (ED21). The Ethical Committee for the Protection of Welfare of Experimental Animals of the Institute for Biological Research "Sinisa Stankovic" Belgrade, Serbia approved all animal experiments (Application No.02-12/13) following the Directive on the protection of animals used for experimental and other scientific purposes (2010/63/EU) and results reported in compliance with the ARRIVE. No randomization was performed to allocate animals in the study. The experimental protocol was not pre-registered.

\section{Tissue preparation and immunohistochemical staining}

Since the pain pathways develop at this time point, to avoid suffering and distress of fetuses, the dams were sacrificed with lethal dose $(200 \mathrm{mg} / \mathrm{kg}$ ) of Nembutal (Serva, Germany). To ensure euthanasia, additionally decapitation of the dams was done. Afterwards, decapitation of fetuses was performed using surgical scissors, and the brains were quickly removed for further analysis. The expert histopathologist determined sex of the fetuses. Researchers performing biochemical, gene and protein studies were blinded to experimental conditions. No exclusion criteria were pre-determined.

The individual fetuses were isolated from the uterus and extra-embryonic membranes. For immunohistochemical analysis, after decapitation the brains were isolated from the skull $(n=3$ per group - Cf, Cm, Df and Dm), cerebellum was removed and fixation in 4\% PFA for 24h was performed, followed by dehydration in a series of sucrose solutions. After cryopreservation, the brains were stored at $-80^{\circ} \mathrm{C}$. Sections, $25 \mu \mathrm{m}$ thick were cut on the cryostat microtome. After hydration of the sections, endogenous peroxidase activity was blocked by incubation in $3 \%$ hydrogen peroxide solution in methanol for 15 min at ambient temperature. Nonspecific background staining was prevented by incubation of the sections with nonimmune, normal donkey serum diluted in phosphate-buffered saline (PBS; $\mathrm{pH} \mathrm{7.4)} \mathrm{for} 60 \mathrm{~min}$, and then previously characterized for specificity primary antibody against NTPDase1/CD39 (Fausther et al. 2007) and eN/CD73 (Fausther et al. 2012) (Table 1) were applied overnight at $4^{\circ} \mathrm{C}$. Furthermore, to validate the antibodies specificity, the isotype-specific immunoglobulins were used (obtained from J.S). After washing in PBS, the sections were incubated with appropriate secondary HRP conjugated antibody (Table 1 ) for $2 \mathrm{~h}$, at room temperature. The immunoreactivity was visualized with $3,3^{\prime}-\mathrm{S}$ -

diaminobenzidinetetrahydrochloride (DAB, Dako, Glostrup, Denmark) as a substrate and cross-sections were counterstained with hematoxylin-eosin (H-E). Incubation without primary antibodies resulted in the absence of any specific reaction. After dehydration and clearing, the tissue was mounted using DPX Mounting medium (Fluka, Buchs, Switzerland), and examined under a Zeiss Axiovert microscope (Carl Zeiss GmbH, Vienna, Austria). 
Using the Atlas of Prenatal Brain Development as a guide (Altman and Bayer 1995), the sections were selected for immunohistochemical staining analysis to get a detailed insight into the position and distribution of immunopositive cells.

Table 1

List of antibodies used in the study. NTPDase1/CD39 - ectonucleoside triphosphate diphosphohydrolase 1; eN/CD73 - ecto-5区-nucleotidase; IHC - immunohistochemistry; WB - Western blot;

\begin{tabular}{|c|c|c|c|}
\hline Antibody & $\begin{array}{l}\text { Source and } \\
\text { type }\end{array}$ & Dilution & Manufacturer \\
\hline \multirow{2}{*}{$\begin{array}{l}\text { NTPDase1/CD39 } \\
\text { rN1-6L(14,15) }\end{array}$} & \multirow{2}{*}{$\begin{array}{l}\text { Rabbit, } \\
\text { polyclonal }\end{array}$} & 1:1000 (IHC) & \multirow[t]{2}{*}{ Ectonucleotidases-ab.com;Cat\# NTPDase1 } \\
\hline & & 1:3000 (WB) & \\
\hline eN/CD73 & \multirow{2}{*}{$\begin{array}{l}\text { Rabbit, } \\
\text { polyclonal }\end{array}$} & 1:2000 (IHC) & \multirow{2}{*}{$\begin{array}{l}\text { Ectonucleotidases-ab.com;Cat\#ecto-5'- } \\
\text { nucleotidase }\end{array}$} \\
\hline rNu-8L $(14,15)$ & & & \\
\hline \multirow[t]{2}{*}{ eN/CD73 } & \multirow{2}{*}{$\begin{array}{l}\text { Rabbit, } \\
\text { monoclonal }\end{array}$} & \multirow[t]{2}{*}{ 1:1 500 (WB) } & Cell Signaling, USA \\
\hline & & & RRID:AB_11217629 \\
\hline$\beta$-actin & $\begin{array}{l}\text { Mouse, } \\
\text { monoclonal }\end{array}$ & $\begin{array}{l}1: 7500 \\
\text { (WB) }\end{array}$ & Sigma A5316 RRID:AB 476743 \\
\hline \multirow{2}{*}{$\begin{array}{l}\text { Anti-rabbit } \\
\text { IgG-HRP- } \\
\text { conjugated }\end{array}$} & \multirow{2}{*}{$\begin{array}{l}\text { Donkey, } \\
\text { polyclonal }\end{array}$} & $1: 250(\mathrm{IHC})$ & \multirow{2}{*}{$\begin{array}{l}\text { Santa Cruz Biotechnology, Santa Cruz, CA, } \\
\text { USA, sc-2313 RRID:AB_641181 }\end{array}$} \\
\hline & & $1: 5000(\mathrm{WB})$ & \\
\hline Anti-mouse & \multirow{2}{*}{$\begin{array}{l}\text { Donkey, } \\
\text { polyclonal }\end{array}$} & \multirow[t]{2}{*}{$1: 250(W B)$} & \multirow[t]{2}{*}{ Santa Cruz sc-2314, RRID:AB_641170 } \\
\hline $\begin{array}{l}\text { IgG-HRP- } \\
\text { conjugated }\end{array}$ & & & \\
\hline
\end{tabular}

\section{Real-time PCR}

After removal of the cerebellum, whole brain tissue ( $n=5$ per group - $C f, C m$, Df, Dm) was used for RNA isolation with TRIzol ${ }^{\circledR}$ reagent (Invitrogen, Carlsbad, CA, USA) following the manufacturer's instructions. Using spectrophotometer RNA purity was determined by measuring $A_{260} / A_{280}$, and $A_{260} / A_{230}$ ratios and RNA concentrations were measured. Reverse transcription was done using the High Capacity cDNA Reverse transcription kit (Applied Biosystems, Foster City, CA, USA) with $1 \mu \mathrm{g}$ of RNA. After synthesis, cDNA was diluted $10 x$ and used for real-time PCR (RT-PCR) with QuantStudioTM 3 Real-Time PCR System (Applied Biosystems, Foster City, CA, USA), by standardized protocol (Jakovljevic et al. 2017). Negative control was obtained by replacing the cDNA template with UltraPure water. Target gene expression was determined by the $2^{-\Delta C t}$ method, using Gapdh (glyceraldehyde-3-phosphate dehydrogenase) as a reference gene. Primer sequences used are shown in Table 2. 
Table 2

Primer sequences. Prtotein encoded by gene Entpd1 - ectonucleoside triphosphate diphosphohydrolase 1; Nt5e-ecto-5囚-nucleotidase; GAPDHglyceraldehyde-3-phosphate dehydrogenase.

\begin{tabular}{|lll|}
\hline Target gene & Forward & Reverse \\
Entpd1 & TCAAGGACCCGTGCTTTTAC & TCTGGTGGCACTGTTCGTAG \\
Nt5e & CAAATCTGCCTCTGGAAAGC & ACCTTCCAGAAGGACCCTGT \\
Gapdh & TGGACCTCATGGCCTACAT & GGATGGAATTGTGAGGGAGA \\
\hline
\end{tabular}

\section{Isolation of crude plasma membrane fraction and whole brain tissue homogenates}

From every pregnant dam ( 5 animals), 3 male and 3 female fetuses were used to isolate tissue homogenates and crude plasma membrane preparations, from whole brain tissue. After removal of the cerebellum, brain tissue was pooled ( 3 male or female brains per preparations) and further processed, which resulted in obtaining $\mathrm{n}=5$ preparations (containing 3 brains) per group (Cf, $\mathrm{Cm}, \mathrm{Df}, \mathrm{Dm})$. For isolation of crude plasma membrane preparation, standardized protocol (Gray and Whittaker 1962) was performed, as previously described (Jakovljevic et al. 2019; Jakovljevic et al. 2017; Lavrnja et al. 2015). Briefly, tissue was homogenized in ice-cold buffered sucrose $(320 \mathrm{mmol} / \mathrm{L}$ sucrose in $5 \mathrm{mmol} / \mathrm{L}$ Tris, $\mathrm{pH}$ 7.4), and then centrifuged at $3.000 \times g$ for $10 \mathrm{~min}$ at $4{ }^{\circ} \mathrm{C}$. From the resulting supernatants, $500 \mu \mathrm{l}$ was transferred into separate microtubes and were further sonicated. Sonication was performed with supernatants, as previously described (Begic et al. 2017), by 3 cycles which included $30 \mathrm{~s}$ of sonication with $5 \mathrm{~s}$ pause between cycles. The resulting whole brain tissue homogenates were stored at $-80^{\circ} \mathrm{C}$ and further used for assesment of oxidative/nistrosative stress parameters, after determination of protein concentration, using Micro BCA Protein Assay Kit.

The remaining supernatants were centrifuged at $12.000 \times g$ for 40 min at $4{ }^{\circ} \mathrm{C}$ and afterwards, precipitated pellets were resuspended in $5 \mathrm{mmol} / \mathrm{L}$ Tris $\mathrm{pH}$ 7.4. The resulting crude plasma membrane preparations were stored at $-80^{\circ} \mathrm{C}$. After determining protein concentration using the Micro BCA Protein Assay Kit (Cat. No. 23235; Thermo Fisher Scientific, Rockford, IL, USA), crude plasma membrane preparations were used for Western blot and ectonucleotidase assays.

\section{Western blot}

Western blot was performed according to previously described procedure (Jakovljevic et al. 2019; Jakovljevic et al. 2017; Lavrnja et al. 2015). Briefly, crude plasma membrane preparations were mixed with 4×Laemmli Sample Buffer (Cat. No. 161-0747 Bio-Rad, Hercules, CA, USA) and then incubated 5 $\mathrm{min} / 95^{\circ} \mathrm{C}$ and cooled on ice. Prepared samples $(15 \mu \mathrm{g}$ of proteins/lane) were loaded on a $7.5 \%$ PAGE- 
SDS gels. After electrophoretic separation, proteins were transferred at $100 \mathrm{mV}$ voltage $/ 1 \mathrm{~h} / 4^{\circ} \mathrm{C}$ to a support membrane (Cat No. 88018 Immobilon-P transfer membrane, Millipore, Darmstadt, Germany). Membranes were blocked using 5 \% Bovine Serum Albumin (Cat. No. A3059 BSA, Sigma, St. Louis, MO, USA) in Tris-buffer saline Tween-20 (TBST). After blocking, membranes were incubated with primary antibodies listed at Table 1 , at $4^{\circ} \mathrm{C}$ overnight. Then, membranes were washed $3 \times 10 \mathrm{~min}$ in TBST and incubated in appropriate IgG-HRP-conjugated secondary antibodies (Table 1 ), for $2 \mathrm{~h}$ at room temperature. For the visualization of a chemiluminescent signal (Cat. No. GERPN2106, ECL, GE Healthcare, USA) X-ray films (Kodak, Rochester, NY, USA) were used. Densitometric analysis was performed using ImageJ software (RRID:SCR_003070). Obtained optical densities (OD) for the band of interest were normalized to OD of $\beta$-actin band and on the same lane, and relative CD39(CD73)/ $\beta$-actin abundances determined from 5 separate membranes were expressed as mean \pm SEM.

\section{Ectonucleotidase Assays}

Nucleotidase activities were evaluated with ATP, ADP and AMP as substrates on samples of $10 \mu \mathrm{g}$ of crude membrane fraction proteins in a final volume of $200 \mu \mathrm{L}$. The hydrolysis of ATP and ADP was tested as previously described (Nedeljkovic et al. 2006) in a reaction medium containing (in mmol/L) 0.5 EDTA, $5 \mathrm{MgCl}_{2}$ and 50 Tris- $\mathrm{HCl} \mathrm{pH}$ 7.4. AMP hydrolysis was assayed following protocol described previously (Lavrnja et al. 2015; Nedeljkovic et al. 2006) in a reaction medium containing (in mmol/L) $10 \mathrm{MgCl}_{2}$ and 100 Tris- $\mathrm{HCl}, \mathrm{pH}$ 7.4. The reaction was initiated with the addition of the substrate at a final concentration of $1 \mathrm{mmol} / \mathrm{L}$ at $37^{\circ} \mathrm{C}$. The reaction was stopped 10 min later by the addition of $20 \mu \mathrm{L}$ of $3 \mathrm{~mol} / \mathrm{L}$ perchloric acid (PCA), and samples were transferred on ice. Released inorganic phosphate (Pi) was determined by the Malachite Green Phosphate assay kit (Cat. No. POMG-25H Bioassay system, Hayward, $\mathrm{CA}, \mathrm{USA}$ ). Assay was run with $\mathrm{n}=5$ tissue preparations per goup (Cf, $\mathrm{Df}, \mathrm{Cm}, \mathrm{Dm}$ ). To reduce random variations, every sample was run in duplicate, and mean value of enzymatic activity was used in further analysis. Every enzymatic assay was performed in three separate determinations. Enzyme activities were expressed as $\mathrm{nmolPi} / \mathrm{min} / \mathrm{mg}$ of protein.

\section{Oxidative/nitrosative stress assesment}

\section{Total Superoxide Dismutase (tSOD) Assay}

The activity of $\mathrm{SSOD}$ (EC 1.15.1.1.) was measured spectrophotometrically in whole brain tissue homogenates, by determining a decrease in the rate of the spontaneous epinephrine autoxidation in alkaline $\mathrm{pH}$ at $480 \mathrm{~nm}$. The kinetics of enzyme activity was measured in $0.1 \mathrm{mM}$ EDTA and $50 \mathrm{mM}$ carbonate buffer pH 10.2 (Serva, Feinbiochemica, Heidelberg, New York), after the addition of $10 \mathrm{mM}$ epinephrine (Sigma, St. Louis, (USA)) as previously described (Djukic et al. 2012; Sun and Zigman 1978). Whole brain preparations ( $\mathrm{n}=5$ per group- $\mathrm{Cf}, \mathrm{Cm}, \mathrm{Df}, \mathrm{Dm}$ ) were asayed in duplicate in 2 independent 
determinations. The results are expressed as units of enzyme activity per mg of total protein $(\mathrm{U} / \mathrm{mg})$, where one unit is the amount of enzyme required for $50 \%$ inhibition of autoxidation of epinephrine.

\section{Catalase (CAT) Assay}

CAT (EC 1.11.1.6.) activity was determined spectrophotometrically in whole brain tissue homogenates by measuring the absorbance of the colored complex formed between ammonium molybdate and $\mathrm{H}_{2} \mathrm{O}_{2}$ at $405 \mathrm{~nm}$ (Góth 1991). The formed yellow complex was determined spectrophotometrically by measuring CAT activity in tissue samples. All samples ( $\mathrm{n}=5$ per group- $\mathrm{Cf}, \mathrm{Cm}, \mathrm{Df}, \mathrm{Dm})$ were run in duplicate in 2 independent determinations. The results are expressed as units of CAT activity per mg of total protein $(\mathrm{U} / \mathrm{mg})$, where one unit is the number of $\mathrm{H}_{2} \mathrm{O}_{2}$ micromols reduced per min $\left(\mu \mathrm{M} \mathrm{H}_{2} \mathrm{O}_{2} /\right.$ min).

\section{Glutathione Peroxidase (GPX) Assay}

GPx (EC 1.11.1.9.) activity in whole brain tissue homogenates was indirectly measured using spectrophotometric determination of NADPH consumption at $340 \mathrm{~nm}$, as previously described (Djukic et al. 2012). Briefly, the method is based on the following principle: GPx catalyzes the reduction of lipid hydroperoxides to their corresponding alcohols using reducing equivalents of $\mathrm{GSH}$, which itself then becomes oxidized. Depleted GSH is regenerated through the reduction of GSSG catalyzed by gluthatione reductase, which utilizes NADPH as a donor of reducing equivalents. In the presence of gluthatione reductase and NADPH, oxidized reduced GSH is immediately converted to the reduced form with concomitant oxidation of NADPH to NADP ${ }^{+}$. All samples ( $n=5$ per group- $\mathrm{Cf}, \mathrm{Cm}, \mathrm{Df}, \mathrm{Dm}$ ) were run in duplicate in 2 independent determinations. The results are expressed as the amount of reduced NADPH per $\mathrm{mg}$ of total protein in the sample \pm SEM.

\section{Determination of total glutathione (tGSH)}

Total GSH (GSH+1/2 GSSG, in GSH equivalents) was determined in whole brain tissue homogenates with DTNB-GSSG reductase recycling assay, as previously described (Bozic et al. 2015). The content of tGSH was spectrophotometrically measured at $412 \mathrm{~nm}$, for $6 \mathrm{~min}$, by 5,5-dithiobis-2-nitrobenzoic acid (DTNB) oxidized glutathione (GSSG) recyclable method. The rate of formation of 5-thio-2-nitrobenzoic acid (TNBA) is proportional to the total glutathione concentration . Oxidized glutathione (GSSG) was used (50 $\mathrm{mmol}$ ) to construct a calibration curve in the range of 0.2-1 nmol / $25 \times 10-6 \mathrm{~mL}(8-40 \mathrm{nmol} / \mathrm{mL})$. Based on the equation of the standard curve, the content of tGSH was calculated and the results are expressed as $\mu \mathrm{mol} \mathrm{GSH} / \mathrm{mg}$ prot. All samples ( $\mathrm{n}=5$ per group- $\mathrm{Cf}, \mathrm{Cm}$, Df, Dm) were run in duplicate, in two separate determinations, and the results are expressed as $\mu \mathrm{mol} \mathrm{GSH} / \mathrm{mg}$ prot.

\section{Determination of $\mathrm{O}_{2}{ }^{\circ-}$ production}


For estimating the concentration of $\mathrm{O}_{2}{ }^{-\cdots}$ in in whole brain tissue homogenates " we used a method described previously (Djukic et al. 2012). Content of $\mathrm{O}_{2}{ }^{--}$was quantified by the method based on the equimolar reduction of nitroblue-tetrazolium (NBT, Sigma-Aldrich, Munich, Germany) to monoformazan by $\mathrm{O}_{2}{ }^{--}$in the alkaline, nitrogen-saturated medium, which aimed to reduce the oxygen tension in the medium. The reduced yellow product was measured spectrophotometrically at $550 \mathrm{~nm}$ (Greenwald 1985). All samples ( $n=5$ per group- $C f, C m, D f, D m$ ) were run in duplicate, in two separate determinations, and the results are expressed as mean reduced NBT ( $\mu \mathrm{M} / \mathrm{mg}$ protein) \pm SEM.

\section{Determination of NO production}

Using the Griess assay, NO production was determined in whole brain tissue homogenates. Because NO is an unstable molecule, it is most common to measure concentrations of its products, nitrites, and nitrates. As previously described (Adzic et al. 2017), at first, we reduced nitrates into nitrites using metallic cadmium (Navarro-Gonzálvez et al. 1998), and then total nitrites were quantified directly spectrophotometrically at $492 \mathrm{~nm}$, using the colorimetric method of Griess. Griess reagent consists of $1.5 \%$ sulfanilamide (Sigma-Aldrich, Munich, Germany) in $1 \mathrm{M} \mathrm{HCl}$ and $0.15 \% \mathrm{~N}-$ (1-naphthyl) ethylendiamine dihydrochloride (Fluka, Buchs, Switzerland) in deionized water. To generate a standard curve, known concentrations of sodium nitrite (Mallinckrodt Chemical Works, St. Luis, MO, USA) were used from which the nitrite concentration in the samples was calculated. All samples ( $n=5$ per group- $C f$, $\mathrm{Cm}, \mathrm{Df}, \mathrm{Dm}$ ) were run in duplicate, in two separate determinations, and the results are expressed as mean concentration of nitrites $(\mathrm{mM} / \mathrm{mg}$ prot $) \pm$ SEM .

\section{Determination of TBARS}

Lipid peroxidation was determined in whole brain tissue homogenates spectrophotometrically, using the thiobarbituric acid reactive species (TBARS) method (Girotti et al. 1991), as previously described (Dejanović et al. 2017). Briefly, the samples were incubated with thiobarbituric acid (TBA) reagent (15\% trichloroacetic acid and $0.375 \%$ TBA, water solution, Merck, Darmstadt, Germany), pH 3.5, at $95^{\circ} \mathrm{C}$. The mixture was heated at $100{ }^{\circ} \mathrm{C}$ for $15 \mathrm{~min}$ and cooled rapidly to room temperature, and the absorbance was measured at $532 \mathrm{~nm}$. All samples ( $\mathrm{n}=5$ per group- $\mathrm{Cf}, \mathrm{Cm}, \mathrm{Df}, \mathrm{Dm}$ ) were run in duplicate, in two separate determinations, and the results are expressed as the mean concentration of $\mathrm{MDA}(\mu \mathrm{mol} / \mathrm{mg}$ protein) \pm SEM.

\section{Data Analysis}

All the data were assessed for homogeneity of variance using Levene's test (SPSS 20, IBM, Armonk, NY, USA). Data normality assessment using the Shapiro-Wilkoxon test, and further statistical analysis using Kruskal - Wallis test followed by Dunn's posthoc test were performed in GraphPad Prism 8 Software® 
(GraphPad Software, La Jolla, CA, USA). $p<0.05$ was considered statistically significant. No test for outliers, nor sample size calculation was performed.

\section{Results}

\section{Ectonucleotidase activities}

ATP-, ADP- and AMP-hydrolysis (Fig. 2a-c) were determined in crude plasma membrane preparations of whole brain tissue, from control and antenatally DEX-treated rat fetuses. Values obtained for ATP hydrolysis $(37.68 \pm 2.18 \mathrm{nmol} / \mathrm{min} / \mathrm{mg}$ and $32.94 \pm 1.06 \mathrm{nmol} / \mathrm{min} / \mathrm{mg})$ in control females and males, respectively, relative to ADP-hydrolysis $(20.77 \pm 2.58$ and $13.88 \pm 1.84 \mathrm{nmol} / \mathrm{min} / \mathrm{mg})$ indicated a major contribution of NTPDase 1 in the rat fetal brain tissue. AMP-hydrolysis, which was similar in control females $(9.64 \pm 0.49 \mathrm{nmol} / \mathrm{min} / \mathrm{mg})$ and males $(6.92 \pm 0.26 \mathrm{nmol} / \mathrm{mg} / \mathrm{min})$, indicated the presence of e5『NT. In males, DEX treatment induced a significant increase in ATP- $(165.60 \pm 5.95 \%, p<0.0001)$, ADP$(218.59 \pm 14.48 \%, p<0.001)$ and AMP-hydrolysing activities $(181.25 \pm 10.76 \%, p<0.0001)$, compared to control animals $(p<0.001)$, while in females all analyzed actonucleotidase activites were similar between DEX-treated and control group.

\section{Gene expression and protein abundance of CD39 and CD73 in rat fetal brain}

Since the obtained values for ATP- and ADP-hydrolysis indicated the presence of NTPDase1/CD39, while AMP-hydrolysing activity was indicative of e5खNT/CD73 expression, by use of RT-PCR and western blotting we next analyzed relative abundance of mRNA (relative to GAPDH) and protein (relative to $\beta$ actin), for both ectonucleotidases in the rat fetal brain. Obtained results (Fig. 3) confirmed the expression of CD39 and CD73 in the rat fetal brain. In control fetuses, relative mRNA and protein abundance for CD39 (Fig 3a,b, respectively) and for CD73 (Fig3c,d, respectively), were similar in the brain of both sexes. In comparison to control fetuses, regarding CD39 expression, DEX treatment induced significant increase $(260.62 \pm 28.28 \%, p<0.001)$ in relative mRNA abundance in males (Fig. 3a), while protein abundance (Fig. $3 b)$ increased more than sixfold in males $(641.04 \pm 98.38 \%, p<0.001)$ and threefold in females (394.64 \pm $44.63, p<0.01$ ). CD73 mRNA abundance (Fig. 3c) was also significantly increased in antenatally DEXtreated female fetuses $(368.50 \pm 38.37, p<0.001)$. On the other hand, after DEX treatment in males, both mRNA and protein expression of CD73 (Fig. 3d) were increased more than 2-fold (222.77 \pm 24.51 and $217.75 \pm 42.64$, respectively; $p<0.05$ ). Two protein bands at $\sim 91$ and $117 \mathrm{kDa}$ were visible on immunoblots probed with anti-CD39 antibody (Fig. 3e), possibly indicating the presence of two glycoform, which combined abundance was determined by densitometric analysis. In immunoblots probed with anti- CD73 antibody (Fig. 3f), one specific band at $~ 70 \mathrm{kDa}$ was observed.

\section{Histological and immunohistochemical analysis}


At the coronal sections of dorsal forebrain region at ED21 six histological zones of the developing cerebral cortex are clearly delineated (Fig. 4a). Histologically the marginal zone (MZ) is positioned below the pial surface and distinctive by mainly acellular appearance. Underneath marginal zone, cortical plate (CP) is visible as a layer of densely packed cells with relatively large nuclei, displaying the radial organization. The next layer of white matter (WM) is distinctive by fewer cells than the previous zone, also showing .radial orientation., Besides, the tangential direction of nerve fibers through WM layer is visible. Below WM is an intermediate zone (IZ) where tangential streams of migratory progenitor cells gives a specific appearance to this region. The subventricular zone (SVZ) and ventricular zone (VZ) appeared densely cellular, occupying the most inner part, which surrounds the lateral ventricles.

\section{Immunohistochemical localization of NTPDase1/CD39 and eN/CD73}

The results of RT-PCR and western blot analysis confirmed the expression of CD39 and CD73 at mRNA and protein level in the brain of rat fetuses at ED21. Therefore, in order to reveal tissue distribution of CD39 and CD73, we performed immunohistochemical staining of coronal cryosections at several regions of interest. Immunohistochemical staining at all analyzed regions (preoptic, optical chiasm region, and retrochiasmatic area) revealed the presence of a small number of scattered CD39- and CD73immunoreactive (IR) cells localized rarely in the sub-plate layer (Fig. $4 \mathrm{~b}-\mathrm{e}, \mathrm{j}-\mathrm{m}$ ), while the most of $I R$-cells were observed in IZ, especially throughout tangential migratory stream (Fig. 4f-i, n-q). Also, very weak immunoreactivity was sporadically observed in the SVZ layer (data not shown). CD39- and CD73-IR cells displayed a similar distribution pattern in physiological controls. Sex-specific differences related to the distribution and number of $I R$ cells were not established. Predominantly, immunopositive cells displayed progenitor-like round-shaped and ellipsoid morphology with the central position of prominent nuclei and individual position into the brain parenchyma (Fig. 4f-i, n-q inset). Despite obtained increase at mRNA and protein level, immunohistochemical staining did not reveal differences regarding frequency and distribution of immunopositive cells between control sections and sections obtained from DEX-treated animals, neither in females nor in males (Fig. 4).,

On the other hand, in the region of fimbria as the principal output bundle of hippocampal nerve fibers, IRcells displayed partly distinctive features. Regarding CD39 (Fig. 5a-d), immunopositive cells were sporadic in control animals of both sexes, while in DEX-treated fetuses, their abundance in border zones of fimbria was increased, especially in males. Also, CD39-IR cells showed bipolar or rarely multipolar morphology (Fig. 5b,d inset), unlike immunopositive cells observed in other regions. In comparison to CD39, CD73-IR cells (Fig. 5e-h) were more abundant in control animals and additionally increased after DEX treatment in the region of fimbria. Unlike CD39-immunopositive cells, CD73-IR cells observed in fimbria were multipolar with several processes (Fig. $5 \mathrm{e}-\mathrm{h}$ inset), indicating a difference either in the type or developmental stage of progenitors expressing these ectonucleotidases. In choroid plexus, immunopositivity was associated with a highly vascularized inner stromal core, which is surrounded by the outer simple cuboidal epithelium, both for CD39 (Fig. 5b,c inset) and for CD73 (Fig 5e,h). 


\section{Oxidative/nitrosative stress assesment}

In order to investigate if the oxidative/nitrosative stress arises after DEX treatment in the fetal brain, we assayed the enzymatic activity of primary antioxidant enzymes, and determined levels of non-enzymatic antioxidant $\mathrm{GSH}$, and pro-oxidants - nitric oxide (NO) and superoxide anion radical $\left(\mathrm{O}_{2}^{\circ}{ }^{\circ}\right)$, as well as lipid peroxidation damage products (TBARS). Our results clearly showed induction of oxidative/nistrosative stress in the fetal brain of both sexes after maternal DEX-treatment (Fig. 6). After DEX treatment, all analyzed antioxidative parameters were significantly decreased in comparison to control fetuses (Fig. 6ad): total SOD activities decreased in males $(79.36 \pm 0.35 \%, p<0,001)$, while decrease in CAT activities was $\sim 10 \%$ in females $(92.07 \pm 0.93 \%, p<0,05)$ and in males $(88.40 \pm 0.88 \%, p<0,01)$. The most pronounced decrease was observed in GPx activities, both in females $(38.97 \pm 1.12 \%, p<0,05)$, and in males $(29.53 \pm$ $0.31 \%, p<0,001)$, while total GSH levels decreased $\sim 25 \%$ in females $(75.80 \pm 0.84 \%, p<0.01)$, and $\sim 40 \%$ in males $(59.65 \pm 0.69 \%, p<0.001)$. Expectedly, levels of pro-oxidants and oxidation damage products were significantly increased in both sexes (Fig. 6e-g): 45\% for $\mathrm{O}_{2}{ }^{--}(141.46 \pm 3.64 \%, \mathrm{p}<0.05$ and $147.57 \pm$ $1.17 \%, p<0.001)$, almost twofold for NO (183.15 $\pm 3.15 \%, p<0.05$ and $195.06 \pm 2.19 \%, p<0.001)$, in females and males, respectively, and for TBARS 50\% in females $(154.75 \pm 1.54 \%, p<0.001)$ and $40 \%$ in males $(138.99 \pm 1.44 \%, \mathrm{p}<0.01)$. Together, obtained results clearly showed induction of oxidative/nistrosative stress in the fetal brain of both sexes after maternal DEX-treatment, altghough with slight bias in males.

\section{Discussion}

The aim of the present study was to explore the effects of antenatal treatment with commonly applied synthetic GC dexamethasone at the expression and enzymatic activity of NTPDase1/CD39 and e5区NT /CD73 in the rat fetal brain of both sexes. Also, we additionally assessed the oxidative status of the fetal brain after antenatal DEX treatment. Briefly, our main findings are the following: 1) DEX treatment induced sex-specific up-regulation of CD39 and CD73 expression and increase in the corresponding enzyme activities, more pronounced in males; 2) CD39- and CD73-IR cells showed similar distribution pattern between treatment groups and genders, being scattered mostly in the intermediate and subventricular zone throughout fetal brain;3) DEX treatment induced oxidative/nitrosative stress in the fetal brain of both sexes.

Due to well-established role of GCs in accelerating organogenesis and maturation, synthetic GCs are frequently administered to women at risk of preterm labor (Moisiadis and Matthews 2014a). In general, GCs promote differentiation at the expense of proliferation (Liggins 1994), especially in regions of active growth in the time of treatment (De Kloet et al. 1988). Multiple animal studies have shown diminishing effects of prenatal synthetic GCs treatment in neurodevelopment such as: pro-apoptotic effects in mice (Noorlander et al. 2008a) and neurodegeneration in rhesus macaques (Uno et al. 1990), impaired radial migration in rat (Fukumoto et al. 2009) and neuronal plasticity (Antonow-Schlorke et al. 2003) in baboon fetal brain, as well as decreased proliferation in hippocampus (Noorlander et al. 2014) and lasting 
microglial remodeling in prefrontal cortex (Caetano et al. 2017) in rodent adults. In line with that, cognitive and attention deficits in adolescent baboons (Rodriguez et al. 2011) and anxiety-like behaviour in rat adult offsping (Caetano et al. 2017; Manojlović-Stojanoski et al. 2020) were reported, Also, clinical studies showed an association of antenatal GCs treatment with alterations of the hypothalamo-pituitaryadrenal axis (Waffarn and Davis 2012), brain structural abnormalities in children (Davis et al. 2013), and in neonates (Tijsseling et al. 2012), as well as with cognitive (Damsted et al. 2011) and behavioural deficits (French et al. 2004) in children.

Most of the cells in the developing brain originate from neural stem/progenitor cells (NSPCs) from VZ/SVZ, which express GR at very early stages, thus enabling the brain to react to premature GC administration (Carson et al. 2016; Tsiarli et al. 2013). Significant gender differences in antenatal DEX treatment outcomes were reported (Alexander et al. 2012; Carbone et al. 2012b), which may be associated with sex-specific responses of NSPCs (Frahm et al. 2018), but also with the differential response regarding the expression of key ectonucleotidases in the rat fetal brain, shown in this study. In contrast to similar expression and tissue distribution of CD39 and CD73 in brain parenchyma of control fetuses, which indicates an essential role of both ectonucleotidases in the rat brain development, DEX treatment induced their sex-specific increase. Overall, up-regulation of analyzed ectonucleotidases was more pronounced in the brain of male fetuses, with an exception of CD73 mRNA increase showing higher statistical significance in females. Also, corresponding ectonucleotidase activities were significantly increased in male fetuses only. Obtained results are in accordance with previously reported up-regulation of CD39 and CD73, and increase in corresponding ectonucleotidase activities in the hippocampus of adult male rats, after repeated low-dose DEX treatment (Drakulić et al. 2015). Additionally, another research groups showed time- and concentration-dependent up-regulation of CD73 in C6 rat glioma cell line (Bavaresco et al. 2007), and increase in NTPDase activities in lymphocytes and platelets from rats (Saucedo et al. 2010) after DEX treatment. Observed effects of DEX treatment at CD73 expression are in line with the presence of sequences specific for GR binding inside the Nt5e gene promoter (Drakulić et al. 2015). On the other hand, absence of GR- binding site and presence of several other regulatory elements in the promoter region of Entpd1 (Drakulić et al. 2015) indicates involvement of another regulatory mechanism in observed DEX-induced up-regulation of CD39

.. Despite undoubted up-regulation of analyzed ectonucleotidases, except partly for the region of fimbria, no visible differences in the number of CD39- and CD73-IR cells between DEX-treated and control fetuses in the brain parenchyma were observed, indicating that obtained increase might have occurred within the same cell subset. Regarding fimbria, CD39-IR cells were more present after maternal DEX treatment especially in male fetuses, while the frequency of distribution of CD73-IR cells was similar between DEXtreated and control fetuses. Nevertheless, CD39- and CD73-positive cells were morphologically distinctive both mutually, and in comparison to other analyzed brain regions, indicating different types of progenitor cells. Namely, it was shown that in the developing dorsal forebrain among immigrant cells, which arrived from the basal forebrain along the same tangential migratory route as GABAergic interneurons, some cells belong to oligodendroglial lineage (He 2001). Among oligodendroglial lineage cells, CD73 expression was associated either with oligodendrocyte progenitor cells (OPC), which typically display 
bipolar morphology, or multipolar differentiating oligodendrocytes, but never with mature oligodendrocytes (Welsh and Kucenas 2018). On the other hand, CD39 expression was associated exclusively with OPCs (Welsh and Kucenas 2018). Such findings may indicate that among multipolar CD73-IR cells and bipolar CD39-IR cells observed in fimbria, at least some cells might belong to immature oligodendroglial lineage pool. However, antenatal DEX treatment induced significant increase in ATP-, ADP- and AMP-hydrolysing activities in male fetus brain. Obtained increase in ectonucleotidase activities suggests paralel decrease in purine nucleotides levels and increase of adenosine in brain parenchyma of DEX-treated male fetuses, which may be particularly pronounced in the pericellular space surrounding groups of CD39- and CD73-IR progenitor cells. Such changes imply effects of antenatal DEX treatment on neurodevelopmental processes exerted via purinergic receptors signaling.

Namely, early embryonic expression was confirmed for several ATP/ADP sensitive purinergic receptors such as P2X7 receptor, which is implicated in the control of unbalanced proliferation through induction of apoptosis of neural progenitor cells (Delarasse et al. 2009; Oliveira et al. 2016), and for $\mathrm{P} 2 \mathrm{Y}_{1}$ receptor, critical in proliferation of radial glia at the peak of neurodvelopment (Weissman et al. 2004) and in migration of both NSPCs (Scemes et al. 2003) and OPC (Agresti et al. 2005). Therefore, DEX-induced increase in ATP/ADP-degrading CD39 in male fetus brain, shown in this study, might interfere with proliferation and migration of neural progenitors, and decrease OPCs migration, through possibly decreased activation of both $\mathrm{P} 2 \mathrm{X} 7$ and $\mathrm{P} 2 \mathrm{Y}_{1}$ receptors. In addition, sustained activation of adenosinergic $A_{1}$ receptor was associated with decrease in axon volume, expression of myelin basic protein (Rivkees and Wendler 2011; Turner et al. 2002b) and consequent reduction in gray and white matter (Turner 2002) in neonatal rats, while inhibition of rapidly-desenzitizing $A_{2 A}$ receptors (Klaasse et al. 2008) diminshed tangential migration of GABAergic interneurons in mice fetuses (Silva et al. 2013). This indicates that increase in adenosine-generating ectonucleotidase cascade, shown in this study, might exert diminishing effects to white and gray matter volume, and interfere with proper integration of GABAergic interneurons. Interestingly, induction of long-lasting sex-dimorphic remodeling of microglia, and consequent cognitive and behavioural deficits in the rat offspring after antenatal DEX treatment, were also associated with $A_{2 A}$ receptor activation (Caetano et al. 2017; Duarte et al. 2019). Taken together, DEX-induced increase in expression of ATP-/ADP-hydrolysing, adenosine-producing ectonucleotidase tandem might diminish normal brain development in male fetuses both via P2 and P1 purinergic receptors.

Beside a role in purinergic signaling, both CD39 and CD73 are involved in cellular adhesion. Previously, Airas (Airas et al. 2000) reported that binding of anti-CD73 mAb induced rapid shedding of CD73 and, similarly to CD39\{Kansas, 1991 \#192\}, increased clustering of LFA1 and consequently increased adhesion of lymphocytes. Adzic (Adzic and Nedeljkovic 2018) showed that both decreased expression and blocking of CD73 induced an increase in the migration of primary astrocytes. In the light of the aforementioned data considering the involvement of CD73 and CD39 in cell adhesion, DEX-induced sexspecific up-regulation of both ectonucleotidases in the rat fetus brain, might suggest decrease in migration of progenitor cells particularly pronounced in male fetuses. 
In addition, our results clearly demonstrated induction of oxidative/nitrosative stress in the rat fetal brain after maternal DEX treatment, in accordance with the data on GC treatment effects from both in vitro experiments in hippocampal and cortical neuronal cultures (Mclntosh and Sapolsky 1996), as well as in vivo experiments in adult rat hippocampus (Sato 2010). On the other hand, a significant decrease in activities of three major antioxidant enzymes, decrease in GSH levels, and increase in pro-oxidants and oxidative damage products levels were induced in both male and female fetus brains in our study, which, despite slight male bias, indicate that oxidative stress induction by DEX treatment was not genderdependent. This also indicates that oxidative stress induction and up-regulation of CD39 in fetal brains shown in the present study are unlikely to be interlinked. However, observed oxidative stress induction as a consequence of DEX treatment, is in line with recently reported blocking of Nrf2-mediated antioxidative cellular protection by GR signaling (Alam et al. 2017). Interestingly, changes in the white matter of fimbria-fornix, as major hippocampal output to the subcortical structures (RajMohan and Mohandas 2007), were induced by GSH deficiency in a mouse model of impaired gluthatione synthesis (Corcoba et al. 2015), a model which is also relevant for schizophrenia and other psychiatric disorders (Elvsåshagen et al. 2013; Fitzsimmons et al. 2009; White et al. 2008), indirectly pointing to the importance of oxidative stress in adverse effects of antenatal DEX treatment.,

Taken together, antenatal DEX treatment induced sex-dependent up-regulation of major ectonucleotidases of the CNS in the fetal brain that was particularly pronounced in males. On the other hand, oxidative/nitrosative stress induction was confirmed in both sexes, indicating weak association between the underlying regulatory mechanisms, but also underlining the involvement of oxidative stress in diminishing neurodevelopmental effects of antenatal DEX treatment. DEX-induced up-regulation of CD39 and CD73 in the rat fetal brain might exert detrimental effects on migration, proliferation, survival and regulatory apoptosis of neural and oligodendroglial progenitors, and induce changes in microglial function, thus potentially diminishing normal brain development. Such effects may be achieved both through the simultaneous decrease in levels of P2, and increase of P1 purinergic receptors ligands, and by interfering with cell adhesion. In summary, observed sex-dependent changes in ectonucleotidase expression may be involved in adverse effects of antenatal DEX treatment on rat neurodevelopment, especially in males, thus contributing to long-lasting cognitive and behavioral outcomes throughout life. Due to involvement of purinergic system in processes that are critical in neurodevelopment, future investigation are needed to determine the exact roles of the changes shown in this study in the effects of antenatal DEX treatment on the brain development.

\section{Declarations}

\section{Funding}

This work was supported by the Ministry of Education, Science and Technological Development, the Republic of Serbia, contract No. 451-03-68/2020-14/200007 and 451-03-68/2020-14/ 200178 and the University of Defense (grant number MFVMA/04/19-21). J.S. received support from the Natural Sciences and Engineering Research Council of Canada (NSERC; RGPIN-2016-05867). 


\section{Conflict of interest}

The authors declare no conflict of interest.

\section{Ethics approval}

The Ethical Committee for the Protection of Welfare of Experimental Animals of the Institute for Biological Research "Sinisa Stankovic" Belgrade, Serbia approved all animal experiments (Application No.02-12/13) following the Directive on the protection of animals used for experimental and other scientific purposes (2010/63/EU) and results reported in compliance with the ARRIVE.

\section{Consent to participate}

Not aplicable.

\section{Consent for publication}

Not aplicable.

\section{Availability of data and material}

The data will be available from corresponding author upon reasonable request.

\section{Code availbility}

Not aplicable.

\section{Authors contributions}

Danijela Laketa, Nadezda Nedeljkovic, Milica Manojlovic - Stojanoski, Irena Lavrnja and Jean Sévigny contributed to study conception and design. Material preparation, data collection and analysis were performed by Danijela Laketa, Milica Manojlovic-Stojanoski, Irena Lavrnja, Ivana Stevanovic, Svetlana Trifunovic, Natasa Ristic and Natasa Nestorovic. The first draft of the manuscript was written by Danijela Laketa and all authors commented on previous version of the manuscript. All authors read and approved the final manuscript.

\section{References}


1. Adzic M, Nedeljkovic N (2018) Unveiling the Role of Ecto-5'-Nucleotidase/CD73 in Astrocyte Migration by Using Pharmacological Tools Frontiers in Pharmacology 9 doi:10.3389/fphar.2018.00153

2. Adzic M et al. (2017) Extracellular ATP induces graded reactive response of astrocytes and strengthens their antioxidative defense in vitro Journal of neuroscience research 95:1053-1066 doi:10.1002/jnr.23950

3. Agresti C et al. (2005) Metabotropic P2 receptor activation regulates oligodendrocyte progenitor migration and development Glia 50:132-144 doi:10.1002/glia.20160

4. Ahlbom E, Gogvadze V, Chen M, Celsi G, Ceccatelli S (2000) Prenatal exposure to high levels of glucocorticoids increases the susceptibility of cerebellar granule cells to oxidative stress-induced cell death Proceedings of the National Academy of Sciences of the United States of America 97:1472614730 doi: $10.1073 /$ pnas. 260501697

5. Airas L, Hellman J, Salmi M, Bono P, Puurunen T, Smith DJ, Jalkanen S (1995) CD73 is involved in lymphocyte binding to the endothelium: characterization of lymphocyte-vascular adhesion protein 2 identifies it as CD73 The Journal of experimental medicine 182:1603-1608 doi:10.1084/jem.182.5.1603

6. Airas L, Niemelä J, Jalkanen S (2000) CD73 Engagement Promotes Lymphocyte Binding to Endothelial Cells Via a Lymphocyte Function-Associated Antigen-1-Dependent Mechanism The Journal of Immunology 165:5411-5417 doi:10.4049/jimmunol.165.10.5411

7. Alam MM et al. (2017) Glucocorticoid receptor signaling represses the antioxidant response by inhibiting histone acetylation mediated by the transcriptional activator NRF2 The Journal of biological chemistry 292:7519-7530 doi:10.1074/jbc.M116.773960

8. Alexander N, Rosenlöcher F, Stalder T, Linke J, Distler W, Morgner J, Kirschbaum C (2012) Impact of antenatal synthetic glucocorticoid exposure on endocrine stress reactivity in term-born children The Journal of clinical endocrinology and metabolism 97:3538-3544 doi:10.1210/jc.2012-1970

9. Altman J, Bayer SA (1995) Atlas of prenatal rat brain development. CRC Press, Boca Raton, Fla.

10. Andersen JK (2004) Oxidative stress in neurodegeneration: cause or consequence? Nature medicine 10 Suppl:S18-25 doi:10.1038/nrn1434

11. Antenatal corticosteroids revisited: repeat courses - National Institutes of Health Consensus Development Conference Statement, August 17-18, 2000 (2001) Obstetrics and gynecology 98:144150 doi:10.1016/s0029-7844(01)01410-7

12. Antonow-Schlorke I, Schwab M, Li C, Nathanielsz PW (2003) Glucocorticoid exposure at the dose used clinically alters cytoskeletal proteins and presynaptic terminals in the fetal baboon brain $\mathrm{J}$ Physiol 547:117-123 doi:10.1113/jphysiol.2002.025700

13. Bailly Y, Schoen SW, Delhaye-Bouchaud N, Kreutzberg GW, Mariani J (1995) 5'-nucleotidase activity as a synaptic marker of parasagittal compartmentation in the mouse cerebellum Journal of neurocytology 24:879-890 doi:10.1007/bf01179986 
14. Bavaresco L, Bernardi A, Braganhol E, Wink MR, Battastini AM (2007) Dexamethasone inhibits proliferation and stimulates ecto-5'-nucleotidase/CD73 activity in $\mathrm{C} 6$ rat glioma cell line Journal of neuro-oncology 84:1-8 doi:10.1007/s11060-007-9342-2

15. Begic A et al. (2017) Disulfiram moderately restores impaired hepatic redox status of rats subchronically exposed to cadmium Journal of enzyme inhibition and medicinal chemistry 32:478489 doi:10.1080/14756366.2016.1261132

16. Birben E, Sahiner UM, Sackesen C, Erzurum S, Kalayci O (2012) Oxidative stress and antioxidant defense The World Allergy Organization journal 5:9-19 doi:10.1097/WOX.0b013e3182439613

17. Bose R, Moors M, Tofighi R, Cascante A, Hermanson O, Ceccatelli S (2010) Glucocorticoids induce long-lasting effects in neural stem cells resulting in senescence-related alterations Cell death \& disease 1:e92 doi:10.1038/cddis.2010.60

18. Bozic I, Savic D, Stevanovic I, Pekovic S, Nedeljkovic N, Lavrnja I (2015) Benfotiamine upregulates antioxidative system in activated BV-2 microglia cells Frontiers in cellular neuroscience 9:351 doi:10.3389/fncel.2015.00351

19. Braun $\mathrm{N}$ et al. (2000) Assignment of ecto-nucleoside triphosphate diphosphohydrolase-1/cd39 expression to microglia and vasculature of the brain European Journal of Neuroscience 12:43574366 doi:10.1111/j.1460-9568.2000.01342.x

20. Burnstock $G$ (2014) Purinergic signalling: from discovery to current developments Exp Physiol 99:1634 doi:10.1113/expphysiol.2013.071951

21. Burnstock G, Dale N (2015) Purinergic signalling during development and ageing Purinergic signalling 11:277-305 doi:10.1007/s11302-015-9452-9

22. Caetano $L$ et al. (2017) Adenosine A2A receptor regulation of microglia morphological remodelinggender bias in physiology and in a model of chronic anxiety Molecular psychiatry 22:1035-1043 doi:10.1038/mp.2016.173

23. Carbone DL, Zuloaga DG, Lacagnina AF, McGivern RF, Handa RJ (2012b) Exposure to dexamethasone during late gestation causes female-specific decreases in core body temperature and prepro-thyrotropin-releasing hormone expression in the paraventricular nucleus of the hypothalamus in rats Physiology \& behavior 108:6-12 doi:10.1016/j.physbeh.2012.07.010

24. Carson R, Monaghan-Nichols AP, DeFranco DB, Rudine AC (2016) Effects of antenatal glucocorticoids on the developing brain Steroids 114:25-32 doi:10.1016/j.steroids.2016.05.012

25. Chan PH (1996) Role of Oxidants in Ischemic Brain Damage Stroke 27:1124-1129 doi:doi:10.1161/01.STR.27.6.1124

26. Chapman K, Holmes M, Seckl J (2013) 11ß-hydroxysteroid dehydrogenases: intracellular gatekeepers of tissue glucocorticoid action Physiological reviews 93:1139-1206 doi:10.1152/physrev.00020.2012

27. Codogno P, Doyennette-Moyne M-A, Aubery M, Dieckhoff J, Lietzke R, Mannherz HG (1988) Polyclonal and monoclonal antibodies against chicken gizzard 5'-nucleotidase inhibit the spreading 
process of chicken embryonic fibroblasts on laminin substratum Experimental cell research 174:344354 doi:https://doi.org/10.1016/0014-4827(88)90305-9

28. Corcoba A et al. (2015) Glutathione Deficit Affects the Integrity and Function of the Fimbria/Fornix and Anterior Commissure in Mice: Relevance for Schizophrenia The international journal of neuropsychopharmacology 19:pyv110 doi:10.1093/ijnp/pyv110

29. Damsted SK, Born AP, Paulson OB, Uldall P (2011) Exogenous glucocorticoids and adverse cerebral effects in children European Journal of Paediatric Neurology 15:465-477 doi:10.1016/j.ejpn.2011.05.002

30. Davis EP, Pfaff D (2014) Sexually dimorphic responses to early adversity: implications for affective problems and autism spectrum disorder Psychoneuroendocrinology 49:11-25 doi:10.1016/j.psyneuen.2014.06.014

31. Davis EP, Sandman CA, Buss C, Wing DA, Head K (2013) Fetal glucocorticoid exposure is associated with preadolescent brain development Biological psychiatry 74:647-655 doi:10.1016/j.biopsych.2013.03.009

32. De Kloet ER, Rosenfeld P, Van Eekelen JAM, Sutanto W, Levine S (1988) Stress, glucocorticoids and development. In: Boer GJ, Feenstra MGP, Mirmiran M, Swaab DF, Van Haaren F (eds) Progress in Brain Research, vol 73. Elsevier, pp 101-120. doi:https://doi.org/10.1016/S0079-6123(08)60500-2

33. Dejanović B, Vuković-Dejanović V, Stevanović I, Stojanović I, Mandić Gajić G, Dilber S (2017) Oxidative stress induced by chlorpromazine in patients treated and acutely poisoned with the drug Vojnosanitetski pregled 73:312-317 doi:10.2298/vsp140423047d

34. Del Puerto A, Wandosell F, Garrido JJ (2013) Neuronal and glial purinergic receptors functions in neuron development and brain disease Frontiers in cellular neuroscience 7:197 doi:10.3389/fncel.2013.00197

35. Delarasse C, Gonnord P, Galante M, Auger R, Daniel H, Motta I, Kanellopoulos JM (2009) Neural progenitor cell death is induced by extracellular ATP via ligation of P2X7 receptor $J$ Neurochem 109:846-857 doi:10.1111/j.1471-4159.2009.06008.x

36. Djukic MM, Jovanovic MD, Ninkovic M, Stevanovic I, llic K, Curcic M, Vekic J (2012) Protective role of glutathione reductase in paraquat induced neurotoxicity Chemico-biological interactions 199:74-86 doi:10.1016/j.cbi.2012.05.008

37. Drakulić D et al. (2015) Upregulation of nucleoside triphosphate diphosphohydrolase-1 and ecto-5'nucleotidase in rat hippocampus after repeated low-dose dexamethasone administration Journal of molecular neuroscience : MN 55:959-967 doi:10.1007/s12031-014-0452-y

38. Duarte JM et al. (2019) Region-specific control of microglia by adenosine A(2A) receptors: uncoupling anxiety and associated cognitive deficits in female rats Glia 67:182-192 doi:10.1002/glia.23476

39. Elvsåshagen T et al. (2013) Evidence for reduced dentate gyrus and fimbria volume in bipolar II disorder Bipolar disorders 15:167-176 doi:10.1111/bdi.12046 
40. Fausther $\mathrm{M}$ et al. (2007) Cloning, purification, and identification of the liver canalicular ecto-ATPase as NTPDase8 Am J Physiol Gastrointest Liver Physiol 292:G785-795 doi:10.1152/ajpgi.00293.2006

41. Fausther M et al. (2012) Coexpression of ecto-5'-nucleotidase/CD73 with specific NTPDases differentially regulates adenosine formation in the rat liver Am J Physiol Gastrointest Liver Physiol 302:G447-459 doi:10.1152/ajpgi.00165.2011

42. Fenoglio C, Scherini E, Vaccarone R, Bernocchi G (1995) A re-evaluation of the ultrastructural localization of 5'-nucleotidase activity in the developing rat cerebellum, with a cerium-based method Journal of Neuroscience Methods 59:253-263 doi:https://doi.org/10.1016/0165-0270(94)00211-X

43. Fitzsimmons J et al. (2009) Diffusion tractography of the fornix in schizophrenia Schizophrenia research 107:39-46 doi:10.1016/j.schres.2008.10.022

44. Flocke K, Lesch G, Elsässer HP, Bosslet K, Mannherz HG (1992) Monoclonal antibodies against 5'nucleotidase from a human pancreatic tumor cell line: their characterization and inhibitory capacity on tumor cell adhesion to fibronectin substratum European journal of cell biology 58:62-70 45.

46. Frahm KA, Waldman JK, Luthra S, Rudine AC, Monaghan-Nichols AP, Chandran UR, DeFranco DB (2018) A comparison of the sexually dimorphic dexamethasone transcriptome in mouse cerebral cortical and hypothalamic embryonic neural stem cells Molecular and cellular endocrinology 471:4250 doi:10.1016/j.mce.2017.05.026

47. French NP, Hagan R, Evans SF, Mullan A, Newnham JP (2004) Repeated antenatal corticosteroids: Effects on cerebral palsy and childhood behavior American Journal of Obstetrics \& Gynecology 190:588-595 doi:10.1016/j.ajog.2003.12.016

48. Fukumoto K, Morita T, Mayanagi T, Tanokashira D, Yoshida T, Sakai A, Sobue K (2009) Detrimental effects of glucocorticoids on neuronal migration during brain development Molecular psychiatry 14:1119-1131 doi:10.1038/mp.2009.60

49. Girotti MJ, Khan N, McLellan BA (1991) Early measurement of systemic lipid peroxidation products in the plasma of major blunt trauma patients The Journal of trauma 31:32-35 doi:10.1097/00005373-199101000-00007

50. Góth L (1991) A simple method for determination of serum catalase activity and revision of reference range Clinica chimica acta; international journal of clinical chemistry 196:143-151 doi:10.1016/0009-8981(91)90067-m

51. Gray EG, Whittaker VP (1962) The isolation of nerve endings from brain: an electron-microscopic study of cell fragments derived by homogenization and centrifugation Journal of anatomy 96:79-88

52. Grkovic I, Bjelobaba I, Nedeljkovic N, Mitrovic N, Drakulic D, Stanojlovic M, Horvat A (2014) Developmental increase in ecto-5'-nucleotidase activity overlaps with appearance of two immunologically distinct enzyme isoforms in rat hippocampal synaptic plasma membranes Journal of molecular neuroscience: MN 54:109-118 doi:10.1007/s12031-014-0256-0

53. Halliwell B (2001) Role of free radicals in the neurodegenerative diseases: therapeutic implications for antioxidant treatment Drugs \& aging 18:685-716 doi:10.2165/00002512-200118090-00004 
54. Halliwell B (2006) Oxidative stress and neurodegeneration: where are we now? J Neurochem 97:1634-1658 doi:10.1111/j.1471-4159.2006.03907.x

55. Jakovljevic M et al. (2019) Induction of NTPDase1/CD39 by Reactive Microglia and Macrophages Is Associated With the Functional State During EAE Frontiers in Neuroscience 13:410

56. Jakovljevic M et al. (2017) Down-regulation of NTPDase2 and ADP-sensitive P2 Purinoceptors Correlate with Severity of Symptoms during Experimental Autoimmune Encephalomyelitis Frontiers in cellular neuroscience 11:333 doi:10.3389/fncel.2017.00333

57. Jobe AH, Soll RF (2004) Choice and dose of corticosteroid for antenatal treatments American journal of obstetrics and gynecology 190:878-881 doi:10.1016/j.ajog.2004.01.044

58. Jozic I, Vukelic S, Stojadinovic O, Liang L, Ramirez HA, Pastar I, Tomic Canic M (2017) Stress Signals, Mediated by Membranous Glucocorticoid Receptor, Activate PLC/PKC/GSK-3 $\beta / \beta$-catenin Pathway to Inhibit Wound Closure The Journal of investigative dermatology 137:1144-1154 doi:10.1016/j.jid.2016.11.036

59. Kaczmarek E et al. (1996) Identification and characterization of CD39/vascular ATP diphosphohydrolase The Journal of biological chemistry 271:33116-33122 doi:10.1074/jbc.271.51.33116

60. Kansas GS, Wood GS, Tedder TF (1991) Expression, distribution, and biochemistry of human CD39. Role in activation-associated homotypic adhesion of lymphocytes Journal of immunology (Baltimore, Md : 1950) 146:2235-2244

61. Klaasse EC, ljzerman AP, de Grip WJ, Beukers MW (2008) Internalization and desensitization of adenosine receptors Purinergic signalling 4:21-37 doi:10.1007/s11302-007-9086-7

62. Kobayashi A, Ohta T, Yamamoto M (2004) Unique function of the Nrf2-Keap1 pathway in the inducible expression of antioxidant and detoxifying enzymes Methods in enzymology 378:273-286 doi:10.1016/s0076-6879(04)78021-0

63. Kukulski $F$ et al. (2005) Comparative hydrolysis of $P 2$ receptor agonists by NTPDases 1, 2, 3 and 8 Purinergic signalling 1:193-204 doi:10.1007/s11302-005-6217-x

64. Lavrnja I, Laketa D, Savic D, Bozic I, Bjelobaba I, Pekovic S, Nedeljkovic N (2015) Expression of a second ecto-5'-nucleotidase variant besides the usual protein in symptomatic phase of experimental autoimmune encephalomyelitis Journal of molecular neuroscience : MN 55:898-911 doi:10.1007/s12031-014-0445-x

65. Liggins GC (1994) The role of cortisol in preparing the fetus for birth Reproduction, fertility, and development 6:141-150 doi:10.1071/rd9940141

66. Liu L et al. (2016) Global, regional, and national causes of under-5 mortality in 2000\&\#x2013;15: an updated systematic analysis with implications for the Sustainable Development Goals The Lancet 388:3027-3035 doi:10.1016/S0140-6736(16)31593-8

67. Manojlović-Stojanoski M et al. (2020) The effects of prenatal dexamethasone exposure and fructose challenge on pituitary-adrenocortical activity and anxiety-like behavior in female offspring Tissue and Cell 62:101309 doi:https://doi.org/10.1016/j.tice.2019.101309 
68. Matthews SG (2000) Antenatal glucocorticoids and programming of the developing CNS Pediatric research 47:291-300 doi:10.1203/00006450-200003000-00003

69. Mattson MP, Lovell MA, Furukawa K, Markesbery WR (1995) Neurotrophic factors attenuate glutamate-induced accumulation of peroxides, elevation of intracellular $\mathrm{Ca} 2+$ concentration, and neurotoxicity and increase antioxidant enzyme activities in hippocampal neurons J Neurochem 65:1740-1751 doi:10.1046/j.1471-4159.1995.65041740.x

70. Mclntosh LJ, Cortopassi KM, Sapolsky RM (1998) Glucocorticoids may alter antioxidant enzyme capacity in the brain: kainic acid studies Brain research 791:215-222 doi:10.1016/s00068993(98)00104-8

71. Mclntosh LJ, Sapolsky RM (1996) Glucocorticoids increase the accumulation of reactive oxygen species and enhance adriamycin-induced toxicity in neuronal culture Exp Neurol 141:201-206 doi:10.1006/exnr.1996.0154

72. Moisiadis VG, Matthews SG (2014a) Glucocorticoids and fetal programming part 1: Outcomes Nature reviews Endocrinology 10:391-402 doi:10.1038/nrendo.2014.73

73. Moisiadis VG, Matthews SG (2014b) Glucocorticoids and fetal programming part 2: Mechanisms Nature reviews Endocrinology 10:403-411 doi:10.1038/nrendo.2014.74

74. Navarro-Gonzálvez JA, García-Benayas C, Arenas J (1998) Semiautomated measurement of nitrate in biological fluids Clinical chemistry 44:679-681

75. Nedeljkovic $\mathrm{N}$ et al. (2006) Up-regulation of ectonucleotidase activity after cortical stab injury in rats Cell biology international 30:541-546 doi:10.1016/j.cellbi.2006.03.001

76. Noorlander CW, Tijsseling D, Hessel EV, de Vries WB, Derks JB, Visser GH, de Graan PN (2014) Antenatal glucocorticoid treatment affects hippocampal development in mice PLoS One 9:e85671 doi:10.1371/journal.pone.0085671

77. Noorlander CW, Visser GH, Ramakers GM, Nikkels PG, de Graan PN (2008a) Prenatal corticosteroid exposure affects hippocampal plasticity and reduces lifespan Dev Neurobiol 68:237-246 doi:10.1002/dneu.20583

78. Oliveira Á, Illes P, Ulrich H (2016) Purinergic receptors in embryonic and adult neurogenesis Neuropharmacology 104:272-281 doi:10.1016/j.neuropharm.2015.10.008

79. RajMohan V, Mohandas E (2007) The limbic system Indian Journal of Psychiatry 49:132-139 doi:10.4103/0019-5545.33264

80. Rivkees SA, Wendler CC (2011) Adverse and protective influences of adenosine on the newborn and embryo: implications for preterm white matter injury and embryo protection Pediatric research 69:271-278 doi:10.1203/PDR.0b013e31820efbcf

81. Robson SC, Sévigny J, Zimmermann H (2006) The E-NTPDase family of ectonucleotidases: Structure function relationships and pathophysiological significance Purinergic signalling 2:409 doi:10.1007/s11302-006-9003-5

82. Rodrigues RJ, Marques JM, Cunha RA (2019) Purinergic signalling and brain development Seminars in cell \& developmental biology 95:34-41 doi:10.1016/j.semcdb.2018.12.001 
83. Rodriguez JS, Zürcher NR, Keenan KE, Bartlett TQ, Nathanielsz PW, Nijland MJ (2011) Prenatal betamethasone exposure has sex specific effects in reversal learning and attention in juvenile baboons American journal of obstetrics and gynecology 204:545.e541-545.e510 doi:https://doi.org/10.1016/j.ajog.2011.01.063

84. Sadej R et al. (2008) Tenascin C interacts with Ecto-5'-nucleotidase (eN) and regulates adenosine generation in cancer cells Biochimica et Biophysica Acta (BBA) - Molecular Basis of Disease 1782:35-40 doi:https://doi.org/10.1016/j.bbadis.2007.11.001

85. Sato H, Takahashi T, Sumitani K, Takatsu H, Urano S (2010) Glucocorticoid Generates RoS to Induce Oxidative Injury in the Hippocampus, Leading to Impairment of Cognitive Function of Rats Journal of Clinical Biochemistry and Nutrition 47:224-232 doi:10.3164/jcbn.10-58

86. Saucedo ÉM et al. (2010) Enzymes that hydrolyze adenine nucleotides in lymphocytes and platelets of immunosuppressed rats Biomedicine \& Pharmacotherapy 64:437-440 doi:https://doi.org/10.1016/j.biopha.2010.01.014

87. Scemes E, Duval N, Meda P (2003) Reduced expression of P2Y1 receptors in connexin43-null mice alters calcium signaling and migration of neural progenitor cells The Journal of neuroscience : the official journal of the Society for Neuroscience 23:11444-11452 doi:10.1523/jneurosci.23-3611444.2003

88. SeckI JR (2001) Glucocorticoid programming of the fetus; adult phenotypes and molecular mechanisms Molecular and cellular endocrinology 185:61-71 doi:10.1016/s0303-7207(01)00633-5

89. Sies H (1985) 1 - Oxidative Stress: Introductory Remarks. In: Sies H (ed) Oxidative Stress. Academic Press, London, pp 1-8. doi:https://doi.org/10.1016/B978-0-12-642760-8.50005-3

90. Sies H (1997) Oxidative stress: oxidants and antioxidants Experimental Physiology 82:291-295 doi:10.1113/expphysiol.1997.sp004024

91. Silva CG et al. (2013) Adenosine Receptor Antagonists Including Caffeine Alter Fetal Brain Development in Mice Science Translational Medicine 5:197ra104-197ra104 doi:10.1126/scitranslmed.3006258

92. Tijsseling D et al. (2012) Effects of Antenatal Glucocorticoid Therapy on Hippocampal Histology of Preterm Infants PLOS ONE 7:e33369 doi:10.1371/journal.pone.0033369

93. Tsiarli MA, Paula Monaghan A, Defranco DB (2013) Differential subcellular localization of the glucocorticoid receptor in distinct neural stem and progenitor populations of the mouse telencephalon in vivo Brain research 1523:10-27 doi:10.1016/j.brainres.2013.06.001

94. Turner CP, Pulciani D, Rivkees SA (2002a) Reduction in Intracellular Calcium Levels Induces Injury in Developing Neurons Experimental Neurology 178:21-32 doi:https://doi.org/10.1006/exnr.2002.8027

95. Turner CP, Yan H, Schwartz M, Othman T, Rivkees SA (2002b) A1 adenosine receptor activation induces ventriculomegaly and white matter loss Neuroreport 13:1199-1204 doi:10.1097/00001756200207020-00026

96. Uno H, Lohmiller L, Thieme C, Kemnitz JW, Engle MJ, Roecker EB, Farrell PM (1990) Brain damage induced by prenatal exposure to dexamethasone in fetal rhesus macaques. I. Hippocampus Brain 
research Developmental brain research 53:157-167 doi:10.1016/0165-3806(90)90002-g

97. Vogel M, Kowalewski HJ, Zimmermann H, Janetzko A, Margolis RU, Wollny HE (1991) Association of the HNK-1 epitope with 5'-nucleotidase from Torpedo marmorata (electric ray) electric organ Biochemical Journal 278:199-202 doi:10.1042/bj2780199

98. Waffarn F, Davis EP (2012) Effects of antenatal corticosteroids on the hypothalamic-pituitaryadrenocortical axis of the fetus and newborn: experimental findings and clinical considerations American journal of obstetrics and gynecology 207:446-454 doi:10.1016/j.ajog.2012.06.012

99. Wallensteen L, Zimmermann M, Thomsen Sandberg M, Gezelius A, Nordenström A, Hirvikoski T, Lajic $S$ (2016) Sex-Dimorphic Effects of Prenatal Treatment With Dexamethasone The Journal of clinical endocrinology and metabolism 101:3838-3846 doi:10.1210/jc.2016-1543

100. Weissman TA, Riquelme PA, Ivic L, Flint AC, Kriegstein AR (2004) Calcium Waves Propagate through Radial Glial Cells and Modulate Proliferation in the Developing Neocortex Neuron 43:647-661 doi:10.1016/j.neuron.2004.08.015

101. Welsh TG, Kucenas S (2018) Purinergic signaling in oligodendrocyte development and function 145:6-18 doi:10.1111/jnc.14315

102. White T, Nelson M, Lim KO (2008) Diffusion tensor imaging in psychiatric disorders Topics in magnetic resonance imaging : TMRI 19:97-109 doi:10.1097/RMR.0b013e3181809f1e

103. Yegutkin GG (2008) Nucleotide- and nucleoside-converting ectoenzymes: Important modulators of purinergic signalling cascade Biochimica et biophysica acta 1783:673-694 doi:10.1016/j.bbamcr.2008.01.024

104. Zimmermann H (1992) 5'-Nucleotidase: molecular structure and functional aspects Biochemical Journal 285:345-365 doi:10.1042/bj2850345

105. Zimmermann H, Zebisch M, Sträter N (2012) Cellular function and molecular structure of ectonucleotidases Purinergic signalling 8:437-502 doi:10.1007/s11302-012-9309-4

\section{Figures}




\section{Dexamethasone \\ $(0,5 \mathrm{mg} / \mathrm{kg} / \mathrm{day}$, \\ subcutaneous injection)}

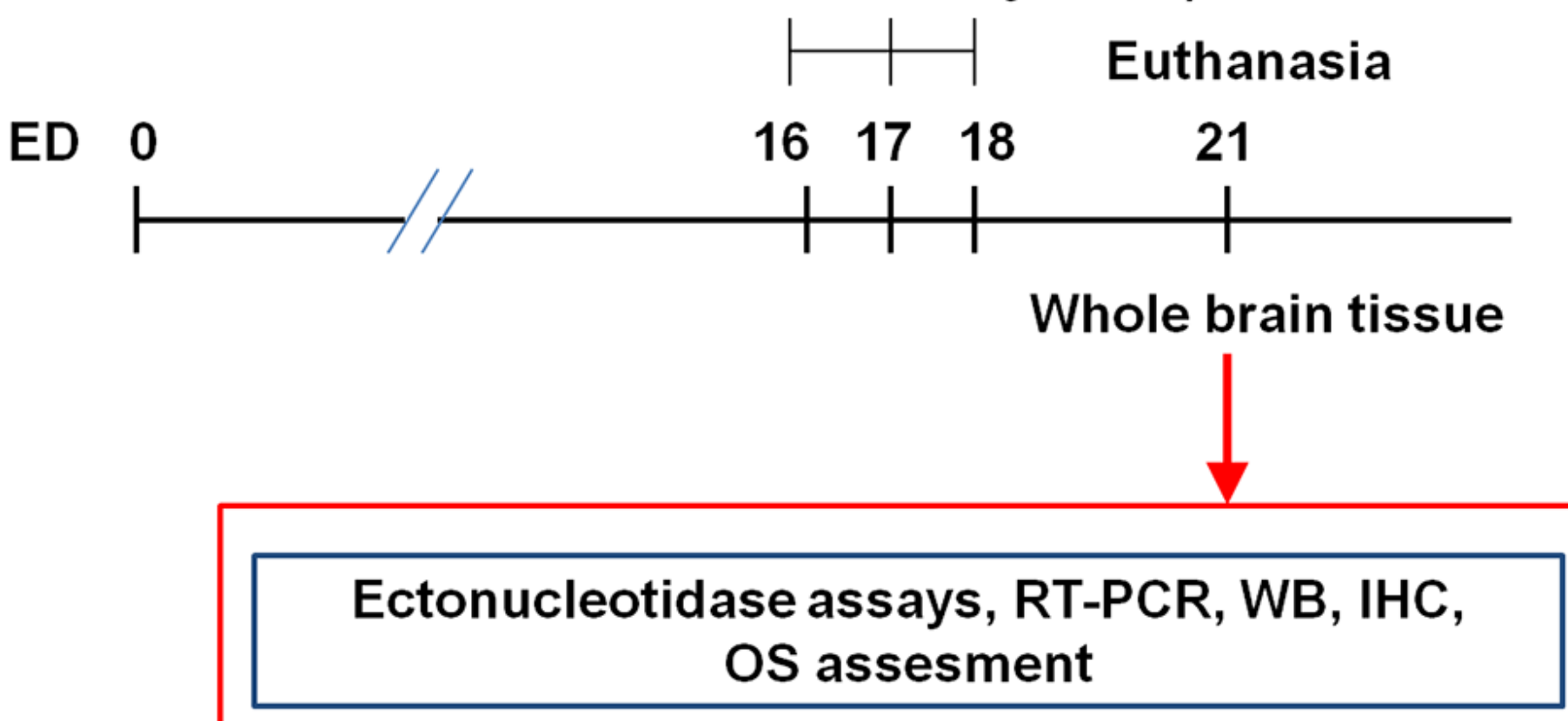

Figure 1

Time-line diagram of the experimental study. ED- embryonic day; RT-PCR - real-time PCR; WB- western blot; IHC - immunohistochemistry; OS - oxidative status. 

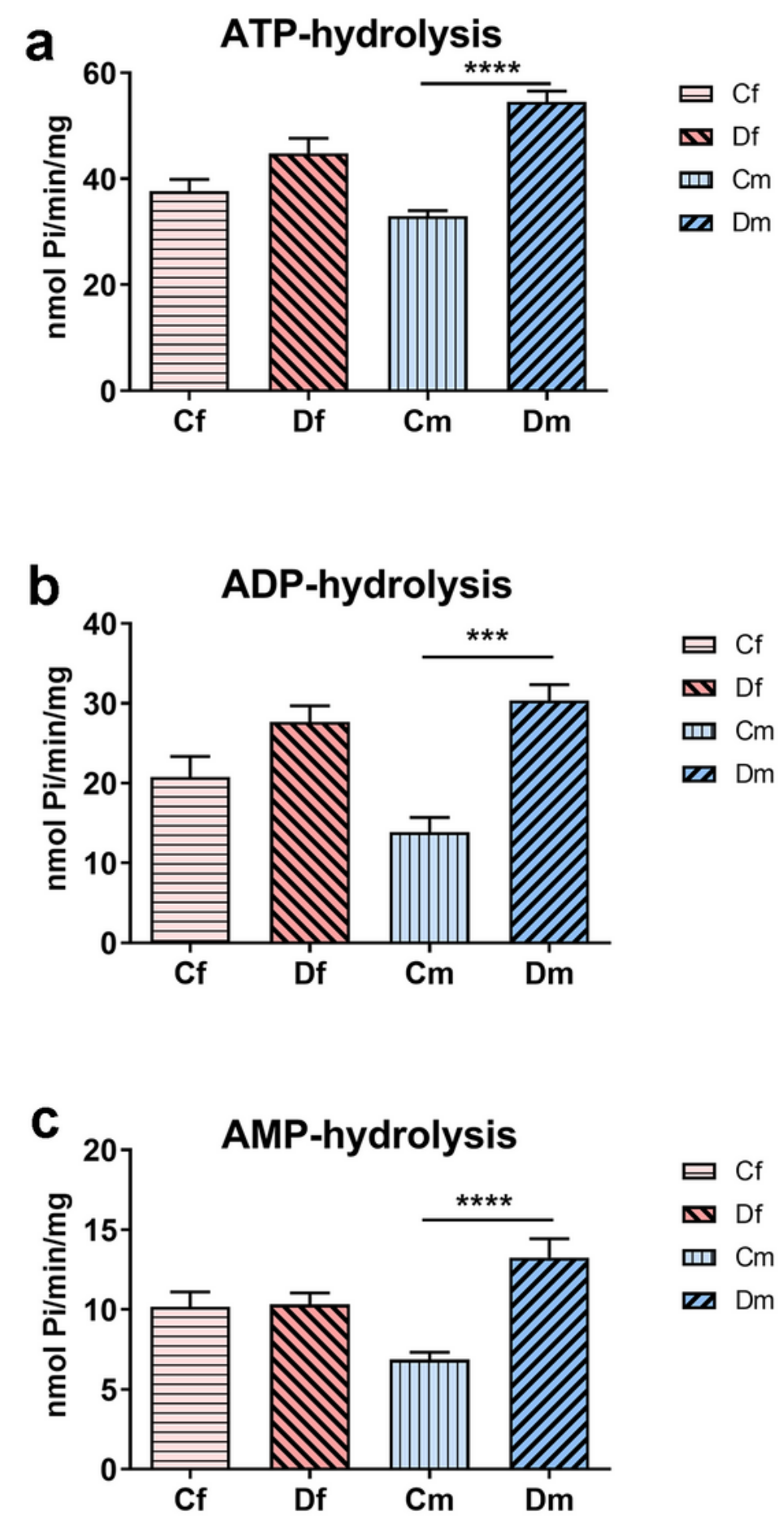

Figure 2

ATP, ADP and AMP-hydrolyzing activities in crude membrane fraction isolated from fetal brain after antenatal DEX treatment. (a) ATP-, (b) ADP- and (c) AMP-hydrolysis was measured in crude plasma membrane preparation of fetal brains. $\mathrm{Cm}, \mathrm{Cf}$ - control male and female fetuses, respectively; Dm, Df DEX-treated male and female fetuses, respectively. For every crude membrane fraction preparation, brain tissue from three fetuses was pooled. $\mathrm{N}=5$ preparations per group (Cf, Df, Cm, Dm) were assayed in 
three separate determinations, and every sample was run in duplicate (mean activity obtained from the duplicate was used in further analysis). The results represent mean specific activities $(\mathrm{nmol} / \mathrm{min} / \mathrm{mg}$ protein) \pm SEM. Statistical significance ${ }^{* \star *} p<0.001,{ }^{* * *} p<0.0001$; Statistical analysis was performed by Kruskal - Wallis test followed by Dunn's post hoc test.

a

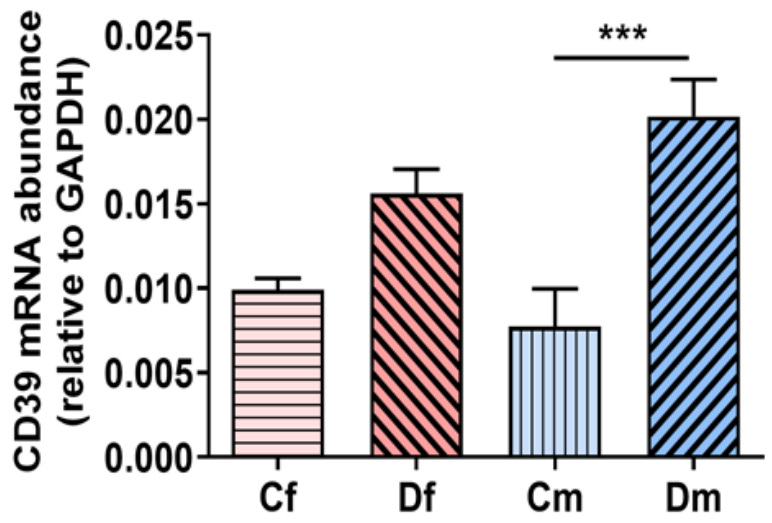

b

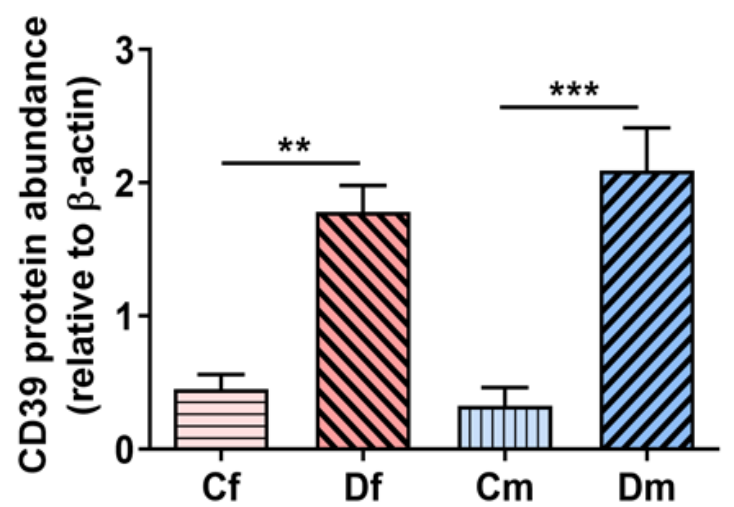

C

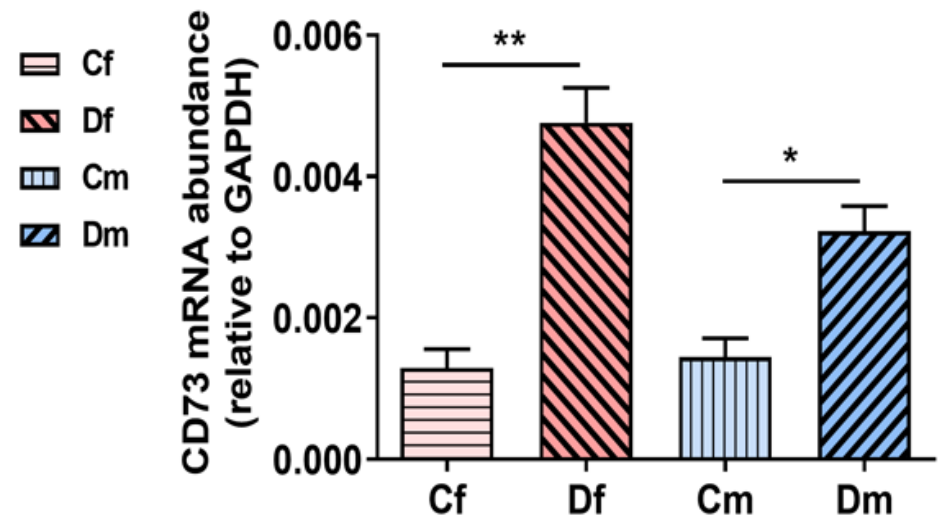

d
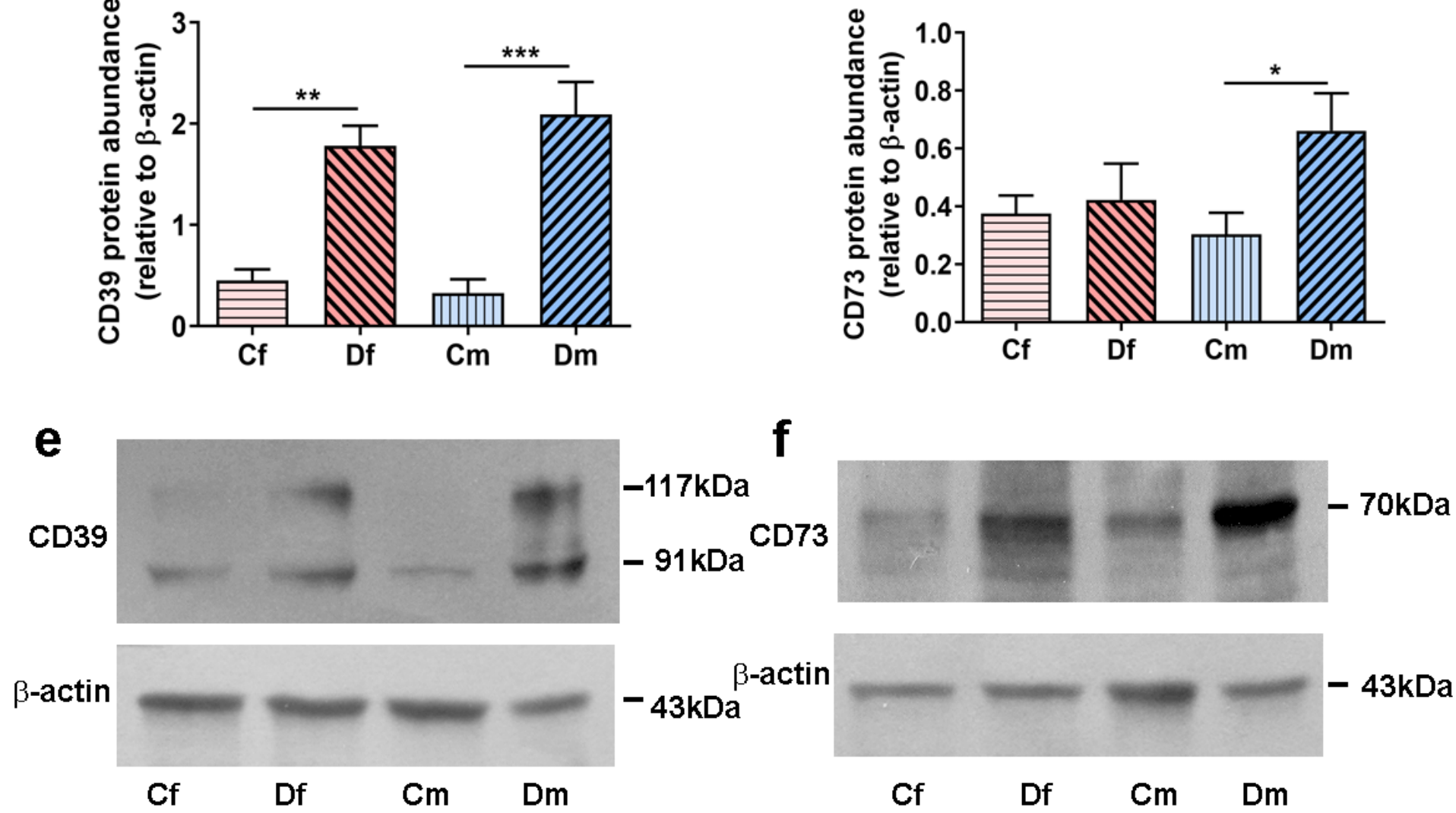

Figure 3

Relative mRNA and protein abundance of CD39 and CD73 in the fetal brain after DEX treatment. (a) CD39 mRNA abundance (relative to GAPDH), and (b) protein abundance (relative to $\beta$-actin); (c) CD73 mRNA 
abundance (relative to GAPDH), and (d) protein abundance (relative to $\beta$-actin); Relative mRNA abundance was determined by RT-PCR, performed in $n=5$ preparations for every group (Cf, Df, Cm an $\mathrm{Dm}$ ), in two separate determinations. Every sample was run in duplicate, and mean Ct value for both target and reference gene (GAPDH) was used in further analysis; Relative protein abundance was determined by densitometric analysis from 5 separate Western blot experiments, in which $n=5$ crude membrane preparations of fetal brains (3 per preparation) for every group (Cf, Df, $\mathrm{Cm}$, and $\mathrm{Dm}$ ) were used. Optical densities (OD) of target protein bands were normalized by OD of $\beta$-actin band in the same lane; For CD39, combined OD of both specific bands was used. Bars represent Mean \pm SEM ; Statistical significance ${ }^{*} \mathrm{p}<0.05,{ }^{*} \mathrm{p}<0.01,{ }^{* \star *} \mathrm{p}<0.001$; Kruskal - Wallis test followed by Dunn's post hoc test. $(\mathrm{e}, \mathrm{f})$ Representative immunoblots of brain tissue preparations obtained by chemiluminescent detection, using X-ray films, of blotted membranes probed with anti-CD39 and -CD73 antibodies, respectively.. Cm, Cf control male and female fetuses, respectively; Dm, Df - DEX-treated male and female fetuses, respectively 


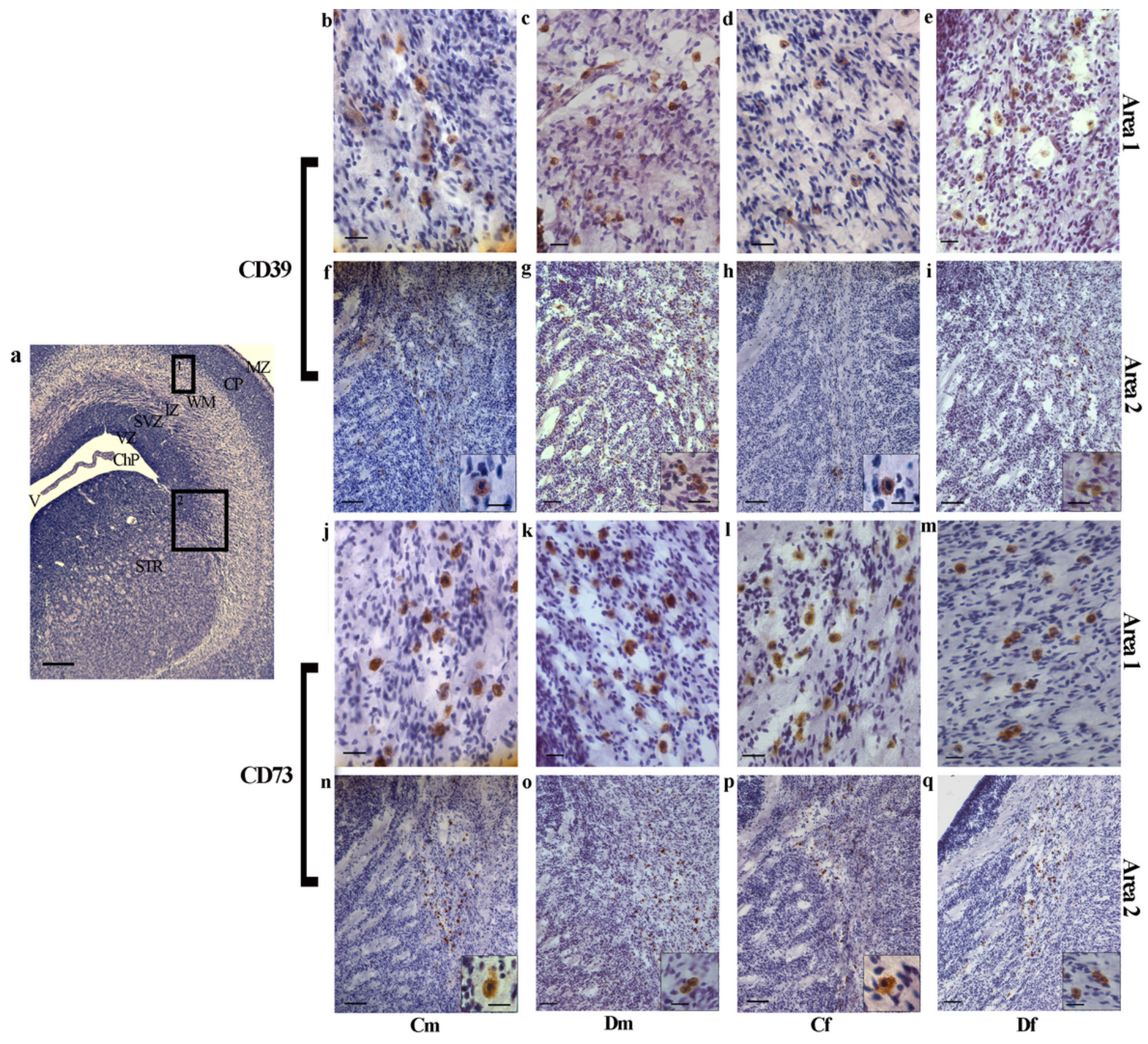

Figure 4

Representative micrographs of immunohistochemical staining of CD39- and CD73-IR cells in rat fetal brain at ED21 in control and antenatally DEX-treated fetuses. (a) Low-power magnification of hematoxylin-eosin stained coronal cross-section at the septal region, showing characteristic layers of the developing brain, which are labeled as follows: VZ-ventricular zone, SVZ-subventricular zone, IZintermediate zone, WM-white matter layer, CP-cortical plate, MZ-marginal zone, V-lateral ventricle, ChPchoroid plexus, STR-striatum. High-power micrographs shown on the left side were obtained from area denoted by rectangles ( 1 - sub-plate in WM region, 2 - IZ encompassing striatum). Scale bar $=400 \mu \mathrm{m}$. (be) Representative micrographs of high-power magnifications of CD39 immunostaining counterstained with hematoxylin-eosin from area denoted by (1) showing mostly round-shaped immunoreactive cells, scattered in the WM layer, and ( $\mathrm{f}-\mathrm{i})$ from the area denoted by (2), showing groups of immunopostive cells 
that are distributed in a pattern resembling to lateral migratory stream; cells are mostly round-shaped with central nuclei (visible in the insets); (j-m), Representative micrographs of high -power magnifications of eN/CD73 immunostaining counterstained with hematoxylin-eosin from area denoted by (1) showing prominently stained immunopositive cells scattered in WM layer, and ( $\mathrm{n}-\mathrm{q})$ from area denoted by (2), showing immunopositive cells grouped in the stream-like pattern in IZ; mostly round-shaped cells with central, prominent nuclei.are visible in the insets. Scale bars: applicable to (b-e) and (j-m) $=25 \mu \mathrm{m}$; aplicable to $(\mathrm{f}-\mathrm{i})$ and $(\mathrm{n}-\mathrm{r})=100 \mu \mathrm{m}$; aplicable to insets $=25 \mu \mathrm{m}$. $\mathrm{Cm}$ and $\mathrm{Cf}$ - - control male and female fetuses, respectively; Dm and Df - antenatally DEX-treated male and female fetuses, respectively.
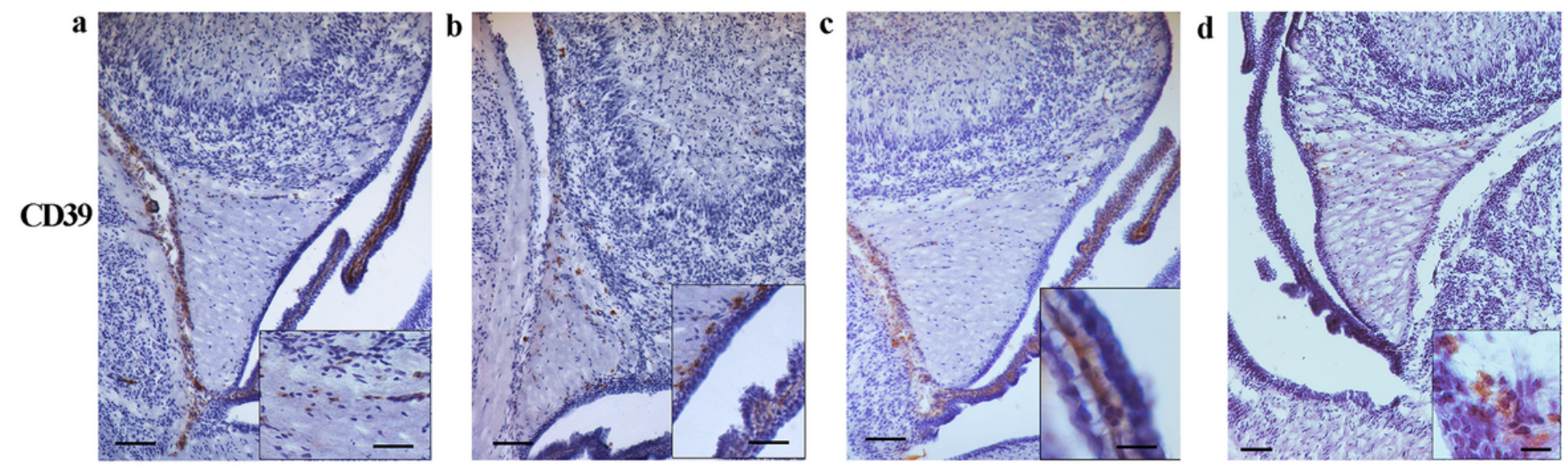

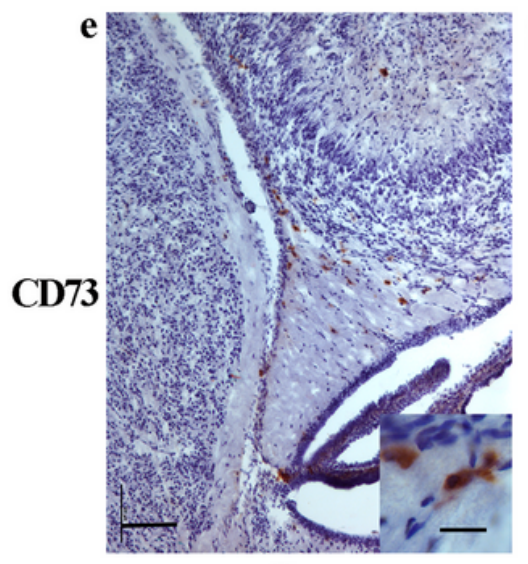

$\mathrm{Cm}$

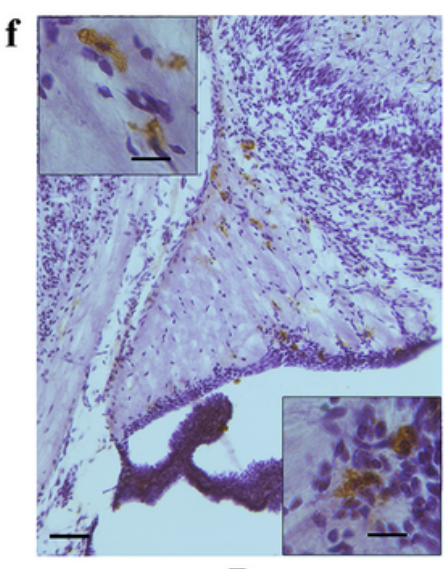

$\mathrm{Dm}$

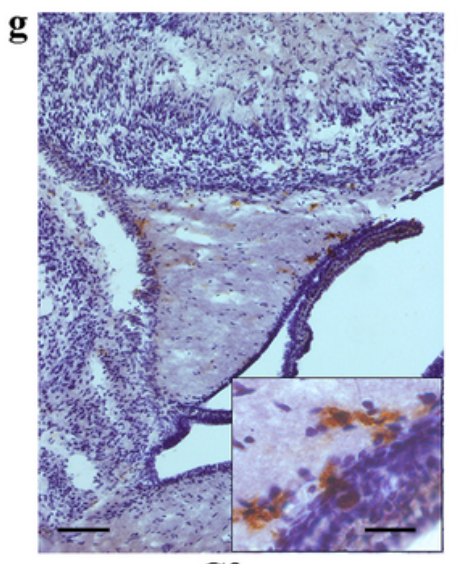

Cf

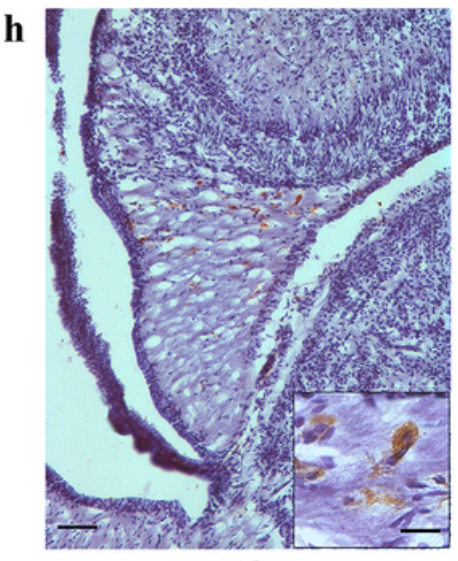

Df

\section{Figure 5}

Representative micrographs of immunohistochemical CD39 and CD73 localization at cross-sections of fimbria at ED21 in control and antenatally DEX-treated rat fetuses. Low-power micrographs of CD39 (a-d) and CD73 (e-h) immunostaining counterstained with hematoxylin-eosin, with high-power micrographs of specific details shown in the inset. $\mathrm{Cm}, \mathrm{Cf}$ - control male and female fetuses, respectively; Dm, Df - DEXtreated male and female fetuses, respectively. Scale bar applicable to all low-power micrographs $=100 \mu \mathrm{m}$; Scale bar applicable to $(a, b)$ insets $=50 \mu \mathrm{m}$; Scale bar aplicable to $(c-h)$ insets $=25 \mu \mathrm{m}$ 

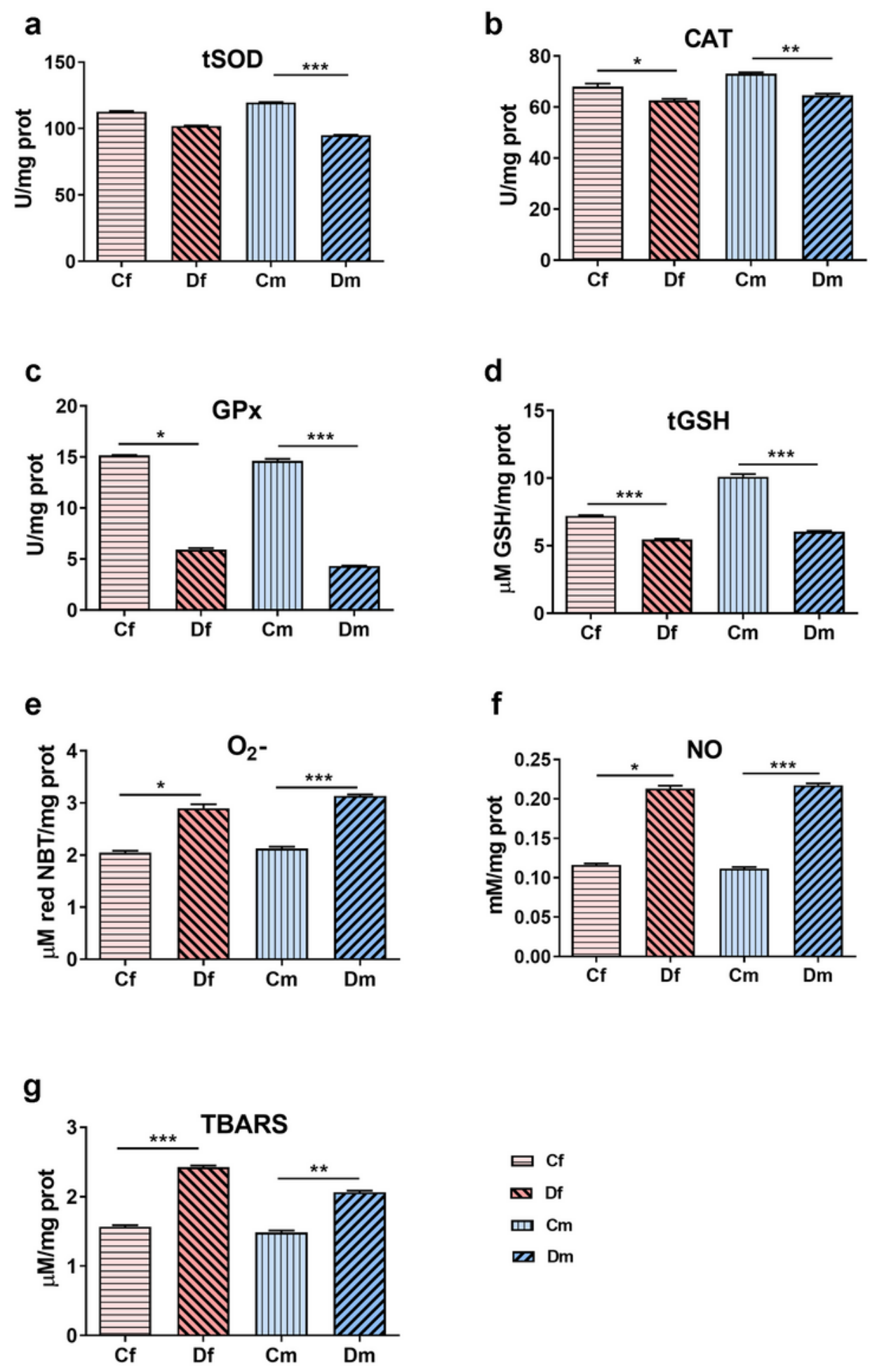

Figure 6

Oxidative / nitrosative status assessment of rat fetal brain after antenatal DEX-treatment. In whole-brain preparations, enzymatic activities of primary antioxidant enzymes SOD (a), TCAT (b) and GPx (c) were assayed, and total levels of nonenzymatic antioxidant GSH (d), and pro-oxidants 02-- (e) and NO (f), together with lipid peroxydation products TBARS (g) were determined. $\mathrm{Cm}, \mathrm{Cf}$ - control male and female fetuses, respectively; Dm, Df - antenatally DEX-treated male and female fetuses, respectively. Bars in 
graphs (a-c) represent Mean specific activity \pm SEM (for antioxidant enzymes) and in graphs (d-g) represent Mean content/mg protein (for anti- and pro-oxidants). Every parameter was determined in $\mathrm{n}=5$ whole brain tissue preparations (pooled from 3 fetuses), for every group (Cf, Df, $\mathrm{Cm}$ and $\mathrm{Dm}$ ), in two separate determinations. All samples were run in duplicate, and mean value was used for further analysis. Statistical significance ${ }^{*} p<0.05,{ }^{* \star} p<0.01,{ }^{* \star *} p<0.001$; Kruskal - Wallis test followed by Dunn's post hoc test.

\section{Supplementary Files}

This is a list of supplementary files associated with this preprint. Click to download.

- Specificityofantibodies.docx 